\title{
¿Las cláusulas sociales en los contratos públicos favorecen a las entidades del tercer sector? La evolución de la contratación pública local en el ámbito de los servicios de atención a las personas en Barcelona ${ }^{1}$
}

\section{Do social clauses in contracts favor third-sector social entities? The evolution of local public procurement in the field of services to people in Barcelona}

\author{
Marc Martí-Costa \\ Instituto de Estudios Regionales y Metropolitanos de Barcelona. UAB (España) \\ ORCID: https://orcid.org/0000-0002-6875-2490 \\ marc.marti@uab.cat
}

\begin{abstract}
NOTA BIOGRÁFICA
Doctor en Políticas Públicas y Transformación Social por la Universidad Autónoma de Barcelona (UAB). Responsable del área de gobernanza del Instituto de Estudios Regionales y Metropolitanos de Barcelona (IERMB). Especialista en análisis y evaluación de políticas públicas y en el estudio de la gobernanza urbana y metropolitana. Actualmente es profesor del Máster en Urbanismo y Ciudad de la Universidad Abierta de Cataluña (UOC) y del Máster Metrópolis del IERMB.
\end{abstract}

Cecilia Isabel Conde López

Instituto de Estudios Regionales y Metropolitanos de Barcelona. UAB (España) ORCID: https://orcid.org/0000-0001-7078-9981 cecilia.conde@uab.cat

\section{NOTA BIOGRÁFICA}

Investigadora del Instituto de Estudios Regionales y Metropolitanos de Barcelona y profesora asociada de la Universidad San Francisco de Quito. Máster en Resolución de Conflictos y Gobernanza por la Universidad de Ámsterdam, ha trabajado en la administración pública local en planificación territorial y estratégica. Sus principales líneas de investigación se centran en conflictos urbanos, participación ciudadana, entre otros temas como contratación pública local.

\section{RESUMEN}

Este artículo presenta la evolución en la contratación pública local en el ámbito de los servicios de atención a las personas en Barcelona, a partir de los cambios introducidos en la legislación y códigos

1 Estudio realizado por el área de gobernanza y políticas públicas del Instituto de Estudios Regionales y Metropolitanos de Barcelona (IERMB), impulsado por La Confederació, patronal del Tercer Sector Social de Catalunya, y que contó con el apoyo económico del Ayuntamiento de Barcelona del Ayuntamiento de Barcelona. 
de buenas prácticas que pretenden acciones positivas hacia la contratación socialmente responsable. En este contexto, se describe la evolución de la naturaleza jurídica de los licitantes y los adjudicatarios, diferenciando entre empresas mercantiles y entidades del tercer sector, para examinar el posible vínculo entre los cambios mencionados y el tipo de licitador y adjudicatario. Para ello, se analizan los contratos en el ámbito de los servicios de atención a las personas realizados entre 2017 y 2019 por el ayuntamiento de Barcelona, institución pionera en la introducción de cláusulas sociales, y se compara con otros siete municipios de Catalunya. Si bien los resultados no identifican una relación positiva entre la introducción de cláusulas sociales con el aumento de las entidades del tercer sector entre los licitadores o los adjudicatarios en Barcelona, si que se aprecia una mayor éxito de las entidades del tercer sector social en los casos que compiten con las empresas mercantiles. Además, el análisis identificó algunos factores que podrían mejorar las posibilidades de éxito de estas entidades sin fines de lucro en los procesos de adjudicación de estos servicios.

\title{
PALABRAS CLAVE
}

Contratación pública; servicio de atención a las personas; entidades del tercer sector social; políticas locales; criterios de adjudicación; cláusulas sociales.

\begin{abstract}
This article presents the evolution of local public procurement in the services to people in Barcelona, based on the changes introduced in the legislation and codes of good practices that seek positive actions towards socially responsible procurement. In this context, the article examines the evolution of the legal nature of the bidders and the successful bidders, differentiating between capitalist enterprises and thirdsector social entities, to determine possible linkage between the changes in the public procurmenent and the type of bidder and successful bidder. For this purpose all contracts in the field of services to people carried out from 2017 to 2019 by the Barcelona city council are analysed and we compare them with seven other municipalities of Catalonia. Despite the fact the results do not find a positive relationship between the introduction of social clauses and the increase in third sector entities among bidders or successful bidders, the third sector entities are more succesful when they compite against capitalist enterpreises in Barcelona. Moreover, the analysis identified some factors that could improve the chances of these non-profit entities to be a successful bidder.
\end{abstract}

\section{KEYWORDS}

Local policies; Public procurement; services to people; third-sector social entities; procurement proceedings; social clauses.

\section{SUMARIO}

INTRODUCCIÓN. 1. METODOLOGÍA. 2. RESULTADOS. 2.1. CAMBIOS INTRODUCIDOS EN LA CONTRATACIÓN PÚBLICA DE LOS CASOS ANALIZADOS, AÑOS 2017-2019. 2.2. CARACTERÍSTICAS DEL PROCEDIMIENTO DE ADJUDICACIÓN. 2.2.1. Peso criterios AFA y Juicios de Valor. 2.2.2. Peso del precio dentro de los criterios AFA. 2.2.3. Peso del precio en el conjunto de la evaluación. 2.2.4. Fórmulas en el proceso de evaluación. 2.3. EVOLUCIÓN EN LA NATURALEZA JURÍDICA DE LOS LICITANTES Y ADJUDICATARIOS. 2.3.1. Evolución de los licitantes. 2.3.2. Evolución de los adjudicatarios. 2.4. EXPLORANDO LA RELACIÓN ENTRE LAS CONDICIONES DE LOS CONTRATOS Y LOS RESULTADOS DE LAS ADJUDICACIONES. 2.5. FACTORES QUE SUPONEN UNA EFECTIVA ACCIÓN POSITIVA HACIA LAS ENTIDADES DEL TERCER SECTOR. CONCLUSIONES. REFERENCIAS BIBLIOGRÁFICAS.

\section{INTRODUCCIÓN}

La crisis económica del 2008 puso sobre la mesa la necesidad de revisar los procesos de contratación pública. La actual crisis sanitaria causada por la pandemia ha puesto de manifiesto, más aún si cabe, la re- 
REALA. Nueva Época - N. 16, octubre 2021 - ISSN: 1989-8975 - DOI: https://doi.org/10.24965/reala.i16.10960 - [Págs. 150-172]

¿Las cláusulas sociales en los contratos públicos favorecen a las entidades del tercer sector? La evolución de la contratación..

Marc Martí-Costa / Cecilia Isabel Conde López

levancia de la responsabilidad social y la sostenibilidad en los diferentes niveles de la administración pública (Solorzano, Navío y Contreras, 2015).

Desde la aprobación de las directivas europeas 2014/23/UE y 2014/24/UE, enmarcadas en la Estrategia 2020 para un crecimiento inteligente, sostenible e integrador (Burzaco Samper, 2016), la contratación pública en el Estado español se ha tenido que adaptar a los cambios producidos en los marcos normativos correspondientes. La transposición de estas directivas en la legislación española a través de la Ley 9/2017, de 8 de noviembre ${ }^{2}$, de contractos del sector público ha marcado un punto de inflexión en este ámbito. La actual Ley de contratos del sector público promueve diversos objetivos de interés público, como por ejemplo la sostenibilidad, la innovación, la responsabilidad social y el fomento de la contratación a pequeñas y medianas empresas y a entidades del Tercer Sector Social (Corretja \& Torrens, 2018; Calvo Vérgez, 2019). Así pues, esta ley se posiciona como un instrumento útil para la consecución de los fines ambientales, energéticos y sociales planteados en la propia ley (Dopazo, 2020). De hecho, la inclusión del valor social en la contratación pública ha ganado peso con relación al criterio económico (Solorzano, Navío y Contreras, 2015).

Para efectos de este artículo, el análisis se va a centrar específicamente en la contratación pública relativa a servicios de atención a las personas. Las entidades vinculadas al tercer sector demandan, desde hace años, un cambio en el modelo en la contratación pública de este tipo de servicios (La Confederació, 2020). Un cambio que permita superar las lógicas basadas, principalmente, en criterios económicos, y que de paso a otros elementos como los relacionados con la calidad del producto/servicios, el trabajo en red o las condiciones laborales del personal que desarrolla el servicio (Fuentes Gasó, 2020; Garrido Juncal, 2017), entre muchos otros elementos que, hasta ahora, se han implementado de forma casi residual.

En Catalunya, en concreto, con la finalidad de mejorar la contratación pública del Servicio de atención a las personas, el año 2015 se firmó el "Código de buenas prácticas en la contratación pública de los servicios de atención a las personas" ${ }^{3}$ por parte de la Generalitat de Catalunya, los sindicatos, las patronales del sector de servicio a las personas, los colegios profesionales vinculados y las entidades representativas del Tercer Sector Social de Catalunya. Este Código pretende, entre otras finalidades, restar peso a los criterios económicos y de capacidad material en los procesos de evaluación y adjudicación de contratos para así incentivar modelos de negocio basados en salarios dignos, en una contratación laboral estable, el comportamiento ético, la igualdad de género, entre otras.

A nivel local también se han dado pasos adelante. Destaca el ayuntamiento de Barcelona con la publicación de la "Guía de contratación pública social" (2018), que impulsa una contratación pública socialmente responsable, incorporando objetivos de justicia social, promoviendo los derechos sociales y laborales de las personas que llevan a cabo estos contratos, e incentivan la economía cooperativa, social y solidaria.

Esta Guía establece que «la contratación pública social no puede perjudicar la concurrencia de las empresas en las licitaciones ni la igualdad de trato. Ninguna de las medidas que se incorporan en esta guía representan una desigualdad de trato de las empresas licitadoras o candidatas en los procedimientos de contratación pública promovidos por el ayuntamiento de Barcelona y el conjunto de entidades con participación mayoritaria municipal que componen su grupo municipal. De todas formas, sí que pretenden una acción positiva a favor de las empresas que demuestren conciencia social y unas buenas prácticas porque estos valores se incorporen en la ejecución del mismo contrato y aumente la eficiencia social, económica e innovadora de la inversión realizada en la compra pública municipal» (Ajuntament de Barcelona, 2018, p. 13).

Por lo tanto, el objetivo de este artículo es explorar si los cambios introducidos en la contratación pública y, en concreto, las mejoras en la contratación pública sostenible impulsadas por parte del Ayuntamiento de Barcelona, han tenido como resultado una mejora en el éxito de las Entidades del Tercer Sector social para la obtención de estos contratos, frente a las empresas mercantiles. Para ello, se realiza un estudio de la evolución de los cambios introducidos en los contratos del ayuntamiento de Barcelona, así como las características de la evaluación de las ofertas, y se contrasta con otros municipios catalanes.

\footnotetext{
2 Ley 9/2017, de 8 de noviembre, de Contratos del Sector Público, por la que se transponen al ordenamiento jurídico español las Directivas del Parlamento Europeo y del Consejo 2014/23/UE y 2014/24/UE, de 26 de febrero de 2014.

3 Codi de bones pràctiques en la contractació pública dels serveis d’atenció a les persones. Dirección General de Contractación Pública de la Generalitat de Catalunya, junio de 2017.
} 
REALA. Nueva Época - N. 16, octubre 2021 - ISSN: 1989-8975 - DOI: https://doi.org/10.24965/reala.i16.10960 - [Págs. 150-172]

¿Las cláusulas sociales en los contratos públicos favorecen a las entidades del tercer sector? La evolución de la contratación..

Marc Martí-Costa / Cecilia Isabel Conde López

Los resultados muestran que, independientemente de la incorporación de nuevas medidas sociales, las empresas mercantiles ganan terreno frente a las entidades del tercer sector social, tanto en volumen de casos, como en volumen presupuestario. En los casos de concurrencia entre empresas mercantiles y entidades del tercer sector, sin embargo, las entidades del tercer sector han mejorado su competitividad, especialmente en relación al volumen presupuestario conseguido. Finalmente, se han identificado también ciertos factores que suponen una efectiva acción positiva hacia las entidades sin ánimo de lucro, como son las entidades del tercer sector.

\section{METOdOLOGÍA}

La metodología de este estudio ha seguido las siguientes fases: delimitación del objeto de estudio, trabajo de campo y, por último, sistematización y análisis de la información extraída del conjunto de documentos de cada caso.

En relación con la primera fase, la delimitación del objeto de estudio se ha desarrollado a partir de tres factores elementales: factor temporal, espacial y de ámbito de actuación. En lo relativo al ámbito temporal se han incluido en la muestra todos aquellos contratos que han sido formalizados entre el 1 de enero de 2017 y el 31 de diciembre de $2019^{4}$. Es a partir de 2017 cuando el pleno funcionamiento de los registros electrónicos de contratación permite realizar un análisis más eficiente y el año 2020 ha sido un año atípico debido a la pandemia producida por la COVID-19. Para este estudio, toda la información se ha obtenido de Plataforma de Contratación Pública de Catalunya, exceptuando algunos contratos de Sabadell relativos al año 2017, que fueron obtenidos de la sede electrónica de su propio sitio web. En cuanto al ámbito territorial, éste se limita a la contratación realizada por el Ayuntamiento de Barcelona, por un lado, y otros siete municipios: Badalona, Girona, l'Hospitalet del Llobregat, Lleida, Sabadell, Tarragona y Terrassa. En su conjunto se incorporan los cuatro municipios más poblados de Catalunya y todas las capitales de provincia, y representan una población de 2.977.145 personas ${ }^{5}$. De estos municipios, son analizados los contratos realizados exclusivamente por el ayuntamiento de cada municipio, sin contar, por tanto, con aquellos realizados por entidades públicas empresariales, organismos autónomos locales o sociedades públicas municipales. A partir de la aplicación de estos parámetros, se han sistematizado un total de 431 casos: 140 correspondientes al año 2017, 142 del 2018 y 149 del año 2019.

La capital catalana presenta un volumen de contratos con un peso del $60,6 \%$ del total de casos; le sigue Girona, con un peso de $8,4 \%$ y Lleida y Sabadell, con un $7.4 \%$. La diferencia entre Barcelona y el resto de los municipios disminuye si atendemos al presupuesto de licitación de los contratos. En función de este factor, el conjunto de los contratos de la capital catalana representa un $64 \%$ del estudio ante un $36 \%$ del resto de ciudades.

El último parámetro de definición del objeto de estudio ha sido el ámbito de actuación de los contratos. Se han elegido todos aquellos contratos dedicados a los Servicios de Atención a las Personas, excluyendo la contratación menor. Para definir qué contratos forman parte de los SAP, se han utilizado las categorías incluidas en los anexos I y II del "Anteproyecto de Ley de Contratos de Servicios a las Personas". Se han aplicado 14 categorías definidas según la propia descripción específica por parte de la administración pertinente en los pliegos contractuales, o del código CPV. La tabla 1 presenta el volumen de casos obtenidos por cada tipo de servicio.

Para la sistematización y el análisis de la información del conjunto de documentos de los contratos, se han atendido en cuenta los siguientes ámbitos: las características del servicio, los aspectos definidos en el procedimiento de valoración de las ofertas y de los proyectos, las características de las candidaturas que se presentaban, los aspectos determinantes en la adjudicación de los contratos y, finalmente, el análisis específico en los casos de concurrencia competitiva entre entidades del TSS y empresas mercantiles.

4 Ante la posibilidad de tomar como fecha de referencia el anuncio de licitación o de formalización, se eligió la segunda, teniendo en cuenta que la formalización del contrato es el procedimiento a través del cual se cierra completamente el proceso de licitación y adjudicación. Esta opción daba mayores garantías a la hora de tener acceso a todos los documentos relativos a los contratos.

5 Idescat, 2020 
REALA. Nueva Época - N. 16, octubre 2021 - ISSN: 1989-8975 - DOI: https://doi.org/10.24965/reala.i16.10960 - [Págs. 150-172] ¿Las cláusulas sociales en los contratos públicos favorecen a las entidades del tercer sector? La evolución de la contratación... Marc Martí-Costa / Cecilia Isabel Conde López

TABLA 1. TIPOS DE SERVICIOS Y NÚMERO DE CASOS

\begin{tabular}{|c|c|c|}
\hline Naturaleza del servicio & Número de casos & $\%$ \\
\hline Otros servicios comunitarios, sociales o personales & 96 & $22,3 \%$ \\
\hline Servicios sociales y de salud & 73 & $16,9 \%$ \\
\hline Servicios de esparcimiento, culturales y deportivos & 66 & $15,3 \%$ \\
\hline Servicios de bienestar y asistencia social & 56 & $13,0 \%$ \\
\hline Servicios de educación y formación profesional & 44 & $10,2 \%$ \\
\hline Otros* & 20 & $4,6 \%$ \\
\hline Servicios de comida para escuelas & 10 & $2,3 \%$ \\
\hline Servicios de gestión de proyectos & 10 & $2,3 \%$ \\
\hline Servicios para la mejora cívica y de apoyo a los Servicios para la comunidad & 9 & $2,1 \%$ \\
\hline Servicios de bibliotecas, archivos, museos y otros servicios culturales & 9 & $2,1 \%$ \\
\hline Servicios especiales de transporte de pasajeros por carretera & 9 & $2,1 \%$ \\
\hline Servicios administrativos en el ámbito del ocio, cultura y religión & 6 & $1,4 \%$ \\
\hline Servicios de orientación y asesoramiento & 5 & $1,2 \%$ \\
\hline Servicios de prevención de accidentes, vigilancia, salvamento y socorrismo & 5 & $1,2 \%$ \\
\hline Prestación de Servicios para la comunidad & 5 & $1,2 \%$ \\
\hline Gestión de Servicios Públicos / Concesión de Servicios & 4 & $0,9 \%$ \\
\hline Servicios medioambientales & 4 & $0,9 \%$ \\
\hline Total general & 431 & $100 \%$ \\
\hline
\end{tabular}

Fuente: Elaboración propia a partir de los datos de la Plataforma de Contratación Pública de la Generalitat.

\section{RESULTADOS}

\subsection{Cambios introducidos en la contratación pública de los casos analizados, años 2017-2019}

Aunque todavía no podemos hablar de un cambio de modelo, si hemos encontrado modificaciones interesantes entre 2017 y 2019. Estos cambios son particularmente significativos especialmente en el ayuntamiento de Barcelona y aportan más información y, sobre todo, mayor claridad sobre los concursos de contratación pública.

En concreto los cambios analizados en este artículo son: 1) inclusión de cláusulas sociales, 2) inclusión de la estructura de costes, 3) incorporación del criterio de puntuación mínima, 4) incremento de los contratos con presupuesto de licitación hasta $100.000 €$, y 5) división del proceso de evaluación de las ofertas en dos bloques principales: criterios AFA y los criterios evaluables mediante juicios de valor.

En primer lugar, se ha detectado un cambio sustancial en la inclusión de las cláusulas sociales. En el caso de Ayuntamiento de Barcelona, éstas se incluyen dentro de la categoría Medidas de Contratación Pública Sostenible (en adelante, MCPS). La siguiente figura muestra un crecimiento en el número de MCPS entre 2017 y 2018, un total de 459 MCPS más. Mientras que entre 2018 y 2019 , hay un crecimiento menor, con un total de 25 MCPS más. 
REALA. Nueva Época - N. 16, octubre 2021 - ISSN: 1989-8975 - DOI: https://doi.org/10.24965/reala.i16.10960 - [Págs. 150-172] ¿Las cláusulas sociales en los contratos públicos favorecen a las entidades del tercer sector? La evolución de la contratación...

Figura 1. Evolución del NúMERo tOtAL DE MCPS EN BARCELONA. 2017-2019

600

500

400

300

200

100

0
510

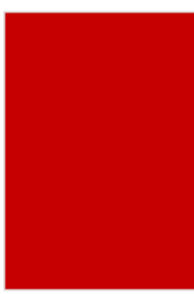

2018
535

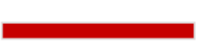

2019

Fuente: Elaboración propia a partir de los datos de la Plataforma de Contratación Pública de la Generalitat.

Tabla 2. Medidas de contratación publica sostenible en Barcelona, 2019

\begin{tabular}{|c|c|c|c|}
\hline & Medidas de Contratación Pública Sostenible & $\begin{array}{l}\text { Número } \\
\text { de casos }\end{array}$ & Porcentaje \\
\hline 1 & Comunicación inclusiva & 52 & $9,7 \%$ \\
\hline 2 & Objeto del contrato con eficiencia social & 45 & $8,4 \%$ \\
\hline 3 & Presupuesto desglosado en costos directos e indirectos & 45 & $8,4 \%$ \\
\hline 4 & Plan o medidas de igualdad & 45 & $8,4 \%$ \\
\hline 5 & Mantenimiento condiciones laborales personas que ejecutan el contrato & 42 & $7,8 \%$ \\
\hline 6 & Valoración del precio máximo definido & 40 & $7,5 \%$ \\
\hline 7 & Pago a precio a empresas subcontratadas & 38 & $7,1 \%$ \\
\hline 8 & Oferta anormalmente baja incumplimiento convenios & 33 & $6,2 \%$ \\
\hline 9 & Mesures contra acoso sexual o razón de sexo & 30 & $5,6 \%$ \\
\hline 10 & Conciliación tiempo familiar y personal & 29 & $5,4 \%$ \\
\hline 11 & Accesibilidad universal & 27 & $5,0 \%$ \\
\hline 12 & Información y subcontratación & 26 & $4,9 \%$ \\
\hline 13 & $\begin{array}{l}\text { Contratación personas en paro o dificultades especiales inserción laboral o } \\
\text { exclusión social }\end{array}$ & 16 & $3,0 \%$ \\
\hline 14 & Criterios de sostenibilidad & 14 & $2,6 \%$ \\
\hline 15 & Salarios de las personas trabajadoras ocupadas en la ejecución del contrato & 13 & $2,4 \%$ \\
\hline 16 & Acreditación de pago en plazo de pago a las empresas subcontratadas & 11 & $2,1 \%$ \\
\hline 17 & Igualdad de oportunidades no discriminación LGTBI & 9 & $1,7 \%$ \\
\hline 18 & Paridad entre hombres y mujeres y categorías profesionales & 8 & $1,5 \%$ \\
\hline 19 & Subcontratación a empresas economía social & 5 & $0,9 \%$ \\
\hline 20 & Subrogación plantilla laboral & 4 & $0,7 \%$ \\
\hline \multirow[t]{2}{*}{21} & Estabilidad: contratación indefinida trabajadores del contrato & 3 & $0,6 \%$ \\
\hline & Total general & 535 & $100 \%$ \\
\hline
\end{tabular}

Fuente: Elaboración propia a partir de los datos de la Plataforma de Contratación Pública de la Generalitat. 
REALA. Nueva Época - N. 16, octubre 2021 - ISSN: 1989-8975 - DOI: https://doi.org/10.24965/reala.i16.10960 - [Págs. 150-172]

¿Las cláusulas sociales en los contratos públicos favorecen a las entidades del tercer sector? La evolución de la contratación...

Marc Martí-Costa / Cecilia Isabel Conde López

Si centramos el análisis en el 2019 encontramos que, de los 82 casos analizados de 2019, en 73 se han incluido MCPS, frente a nueve casos en los que no constaban. La media de este tipo de cláusulas ha crecido 0,9 puntos (con respecto a años anteriores), hasta llegar a las 6,5 por caso. De hecho, muchas de las MCPS están presentes en más de la mitad de los casos de 2019. Entre las MCPS más comunes destacan: comunicación inclusiva $(9,7 \%)$, plan de igualdad $(8,4 \%)$ y presupuesto desglosado en costos directos e indirectos $(8,4 \%)$. Por otro lado, entre las menos comunes, se encuentra la subcontratación a empresas de economía social $(0,9 \%)$, subrogación de plantilla laboral $(0,7 \%)$ y, finalmente, contratación indefinida al personal del contrato $(0,6 \%)$.

Entre estas medidas, cabe destacar la cláusula social relativa a la valoración del precio máxima definida en un $35 \%$ del total de la oferta, por su vínculo con el análisis que se realizará a continuación. La evolución de esta medida presenta una tendencia decreciente en el 2019, en comparación al 2018; un año en el que esta medida experimentó un crecimiento exponencialmente. De hecho, en el 2018 , el $86,2 \%$ de los casos de Barcelona, presentaban un peso del precio igual o inferior al $35 \%$; y en el 2019 , un $82,9 \%$.

Figura 2. Distribución de los CASOS En FUnción del PESO del PRECIO EN BARCELONA 2017-2019

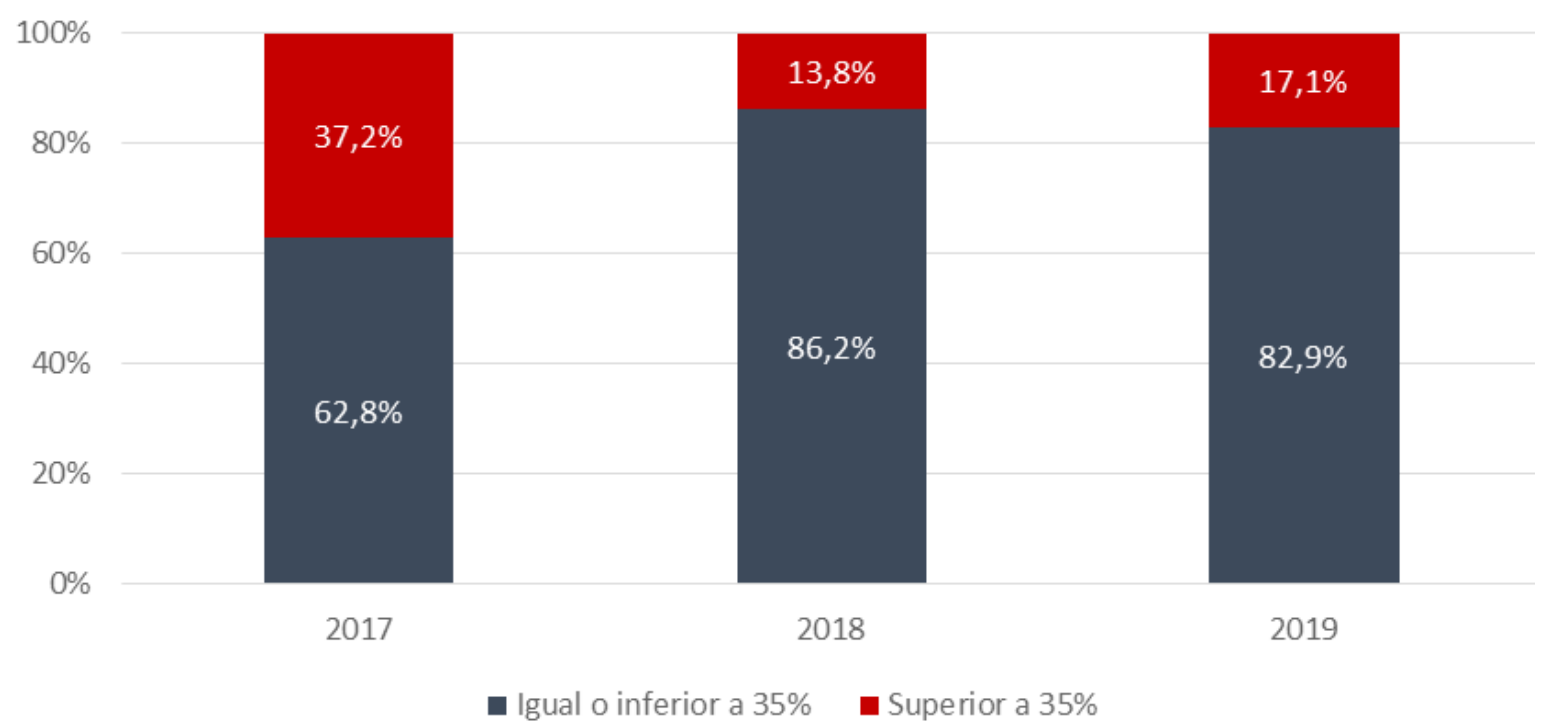

Fuente: Elaboración propia a partir de los datos de la Plataforma de Contratación Pública de la Generalitat.

En segundo lugar, otra novedad en la contratación pública es la descripción de la estructura de costes de los servicios, que se ha convertido en una información disponible en la mayor parte de los pliegues administrativos, no solo en Barcelona, sino en la mayoría de los municipios, aplicando el artículo 100.2 de la Ley 9/2017, que prevé esta disposición. Este dato es revelador en tanto en cuanto hasta 2018, en el resto de los municipios, no siempre se encontraba esta información. Contar con esta información es importante ya que permite comprobar cuáles son los costes directos e indirectos considerados $y$, por ende, conocer si los salarios del personal han sido calculados en función de un convenio colectivo específico y su adecuación al servicio.

En tercer lugar, es importante considerar también la inclusión del criterio de una puntuación mínima en la evaluación para que se evalúe la oferta, en los pliegues contractuales. Este criterio tiene mucho sentido, ya que se trata de una medida para exigir un mínimo de calidad en las ofertas presentadas. De todas formas, a pesar de que este criterio ha crecido significativamente entre 2017 y 2019 , sigue siendo minoritario, y se concentra mayoritariamente en los casos de la capital catalana $(90,9 \%)$.

En cuarto lugar, también es relevante observar la evolución de los rangos presupuestarios ${ }^{6}$ de este tipo de contratos. Se evidencia un considerable aumento en el volumen de la contratación con presupuesto de

6 Los rangos presupuestarios se dividen en cuatro categorías: contratos con presupuesto de licitación + IVA inferior a 100.000€, contratos entre 100.001 y $500.000 €$, contratos entre $500.001 €$ y 1 millón; contratos de más de un millón. 
REALA. Nueva Época - N. 16, octubre 2021 - ISSN: 1989-8975 - DOI: https://doi.org/10.24965/reala.i16.10960 - [Págs. 150-172]

¿Las cláusulas sociales en los contratos públicos favorecen a las entidades del tercer sector? La evolución de la contratación..

Marc Martí-Costa / Cecilia Isabel Conde López

licitación hasta $100.000 € y$, por otra parte, una disminución del número de contratos de entre $100.001 €$ hasta 1 millón de euros. Los casos que superan la cifra de un millón presentan un ligero ascenso en el 2019.

Figura 3. Evolución RANGos PRESUPUESTARIOS DEL CONJUNTO DE LOS CASOS, 2017-2019

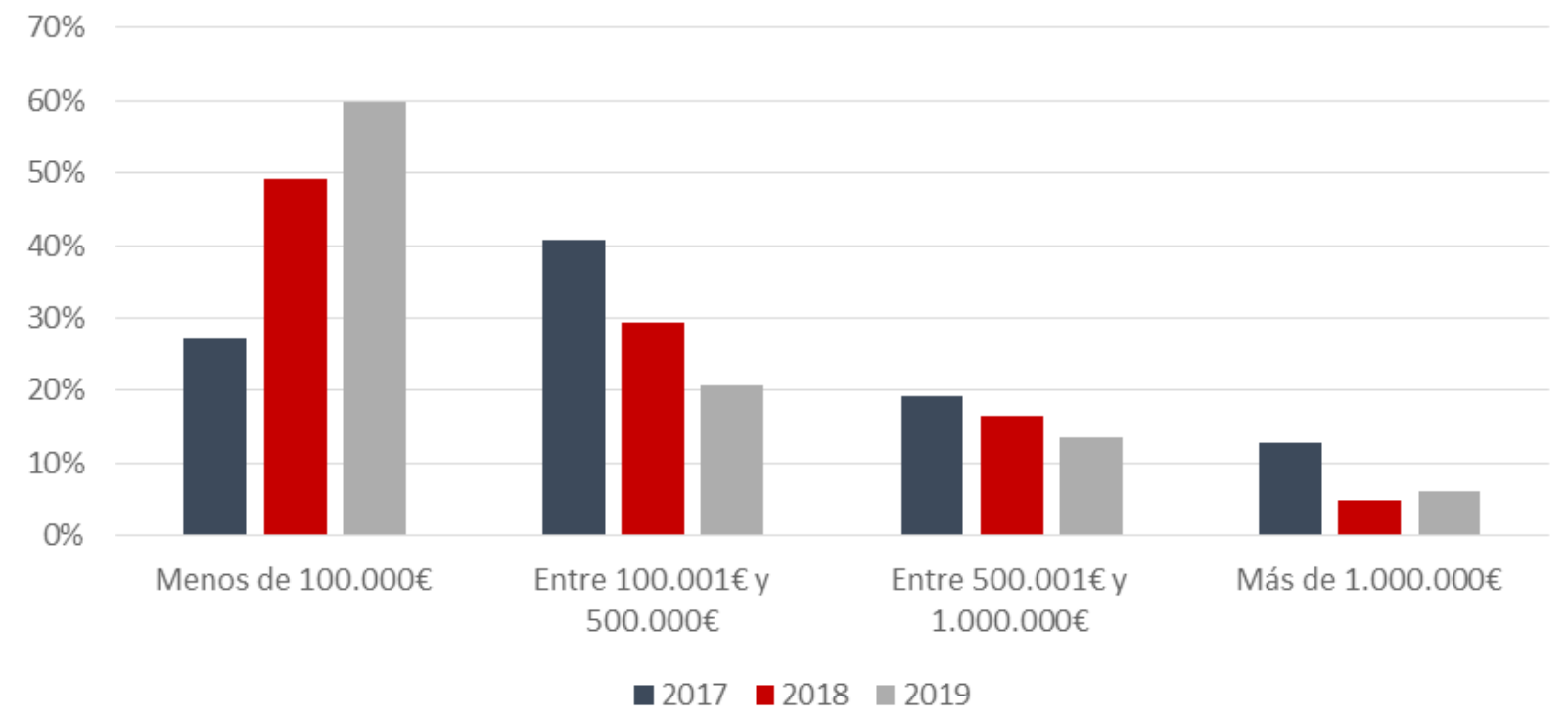

Fuente: Elaboración propia a partir de los datos de la Plataforma de Contratación Pública de la Generalitat.

En quinto puesto, cabe destacar también que, actualmente, la división en dos bloques de la estructura del proceso de evaluación de las ofertas y de adjudicación: los criterios evaluables de forma automática (en adelante, AFA) y los criterios evaluables mediante juicios de valor (en adelante, JdV) (algo que, tradicionalmente, se dividía entre el precio y la propuesta técnica). Los criterios AFA tienen como finalidad evaluar de forma objetiva los aspectos a valorar y su correspondiente puntuación, a través de una fórmula matemática o de una descripción detallada. Algunos ejemplos de estos criterios AFA son la ampliación del servicio o de las actividades dentro del mismo precio; incremento de los recursos humanos; volumen de personal fijo dentro de la plantilla. Generalmente, la valoración de estos criterios se incluye en los pliegos administrativos, en tablas de equivalencia donde se consideran los tramos de estos criterios y su correspondiente puntuación.

Los criterios evaluables mediante JdV dependen de una valoración más subjetiva, o quizá menos automática, de las ofertas. Para hacer esta valoración, se pide una descripción de estos elementos y la mesa de contratación evalúa el grado de idoneidad de la propuesta. Normalmente, en el bloque de los JdV constan cuestiones como la organización del servicio, los métodos de trabajo, la coordinación, la propuesta técnica, trabajo con otros agentes del territorio, etc.

\subsection{Características del procedimiento de adjudicación}

La estructura del proceso de evaluación incluye elementos esenciales a la hora de analizar la contratación pública, ya que determinan, por un lado, qué empresa o entidad será la encargada de llevar a cabo el objeto del contrato (el servicio) y, por otro lado, cuáles son las características del contrato y de su implementación/ejecución.

\subsubsection{Peso criterios AFA y Juicios de Valor}

En el período analizado, los criterios AFA presentan un peso mayor que los JdV en el conjunto de criterios evaluadores. En general, el peso medio de los criterios AFA en los casos del ayuntamiento de Barcelona supera el $50 \%$ en todos los años, con un significativo aumento en el 2019. Esta misma tendencia se replica en el resto de los municipios analizados. 
REALA. Nueva Época - N. 16, octubre 2021 - ISSN: 1989-8975 - DOI: https://doi.org/10.24965/reala.i16.10960 - [Págs. 150-172] ¿Las cláusulas sociales en los contratos públicos favorecen a las entidades del tercer sector? La evolución de la contratación...

Marc Martí-Costa / Cecilia Isabel Conde López

Figura 4. Peso de los criterios afa y JdV en los expedientes analizados DE LA CIUDAD DE BARCELONA, 2017-2019

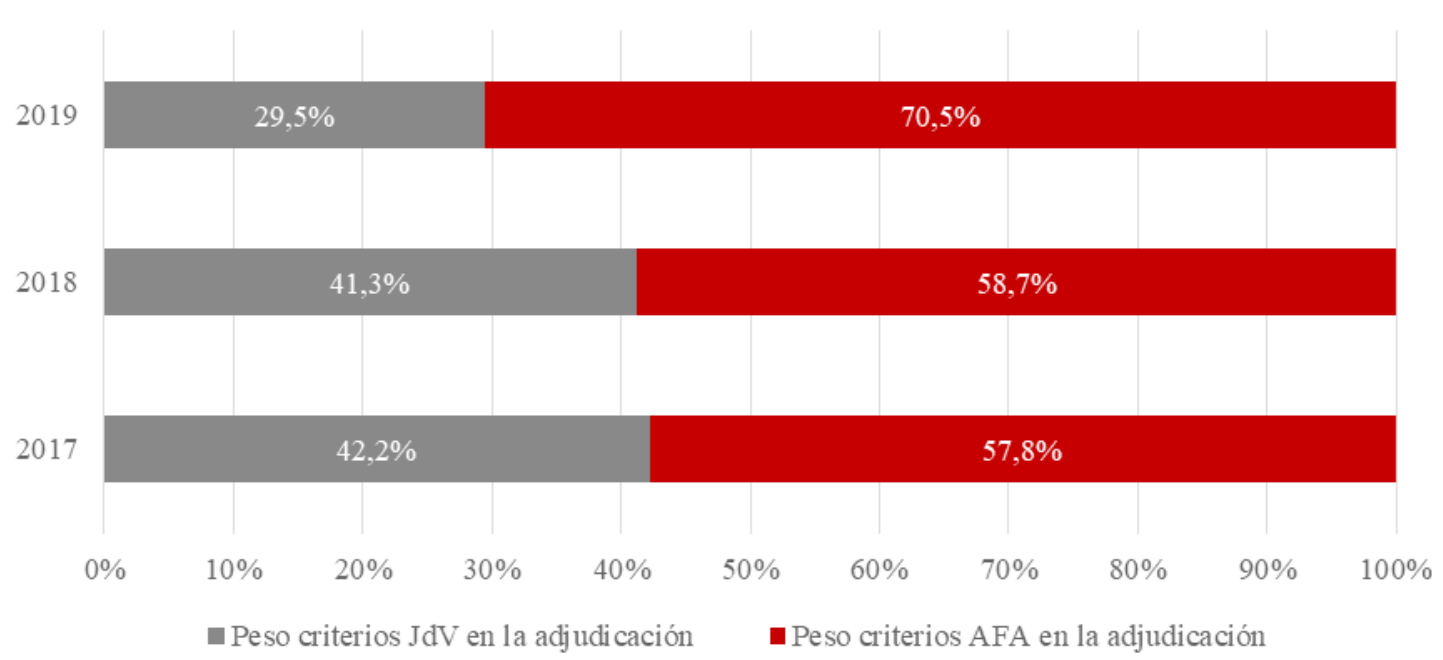

Fuente: Elaboración propia a partir de los datos de la Plataforma de Contratación Pública de la Generalitat.

El aumento en el peso de los AFA se puede explicar explorando los datos de forma territorial. En BarceIona, los criterios AFA llegan al 70,5\% en el 2019. En cuanto al resto de municipios, la tendencia se repite, con la única diferencia de que los criterios AFA reciben un peso muy significativo en el 2019, llegando al $78,1 \%$. En cuanto a los criterios evaluables mediante JdV, representan alrededor de un $40 \%$ entre 2017 y 2018, pero cae el porcentaje en 2019 hasta un 29,5\% (Figura 5).

\section{Figura 5. EVolución del Peso de los CRITERIOS eVAluables MEdiante Juicios de VALOR (JDV) EN LOS EXPEDIENTES ANALIZADOS SEGÚN TERRITORIO, 2017-2019}

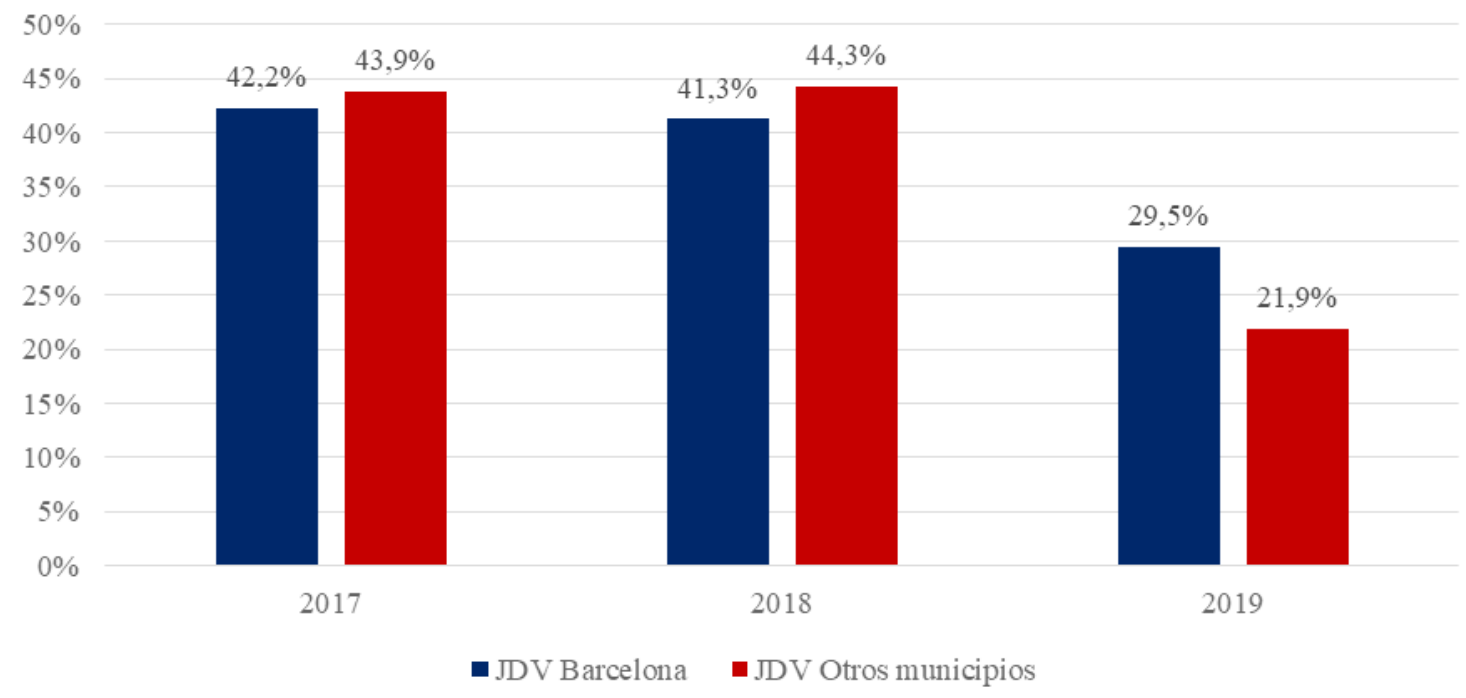

Fuente: Elaboración propia a partir de los datos de la Plataforma de Contratación Pública de la Generalitat.

\subsubsection{Peso del precio dentro de los criterios AFA}

Dentro de los criterios AFA, el precio es el factor con más peso ya que, entre 2017 y 2019, representa un $64,9 \%$, frente al $35,1 \%$ de peso que tienen el resto de los criterios AFA. Este peso, aunque varía en función del municipio, se ha ido reduciendo en todas las ciudades si comparamos con el dato inicial de 2017 (excepto en Badalona)(Figura 6). Barcelona es, con diferencia, la ciudad que menos peso otorga al precio dentro de los criterios AFA $(47,7 \%)$. 
Figura 6. EVolución del PESO del PRECIO deNTRO de LOS CRITERIOS AFA SEGÚN MUNICIPIOS

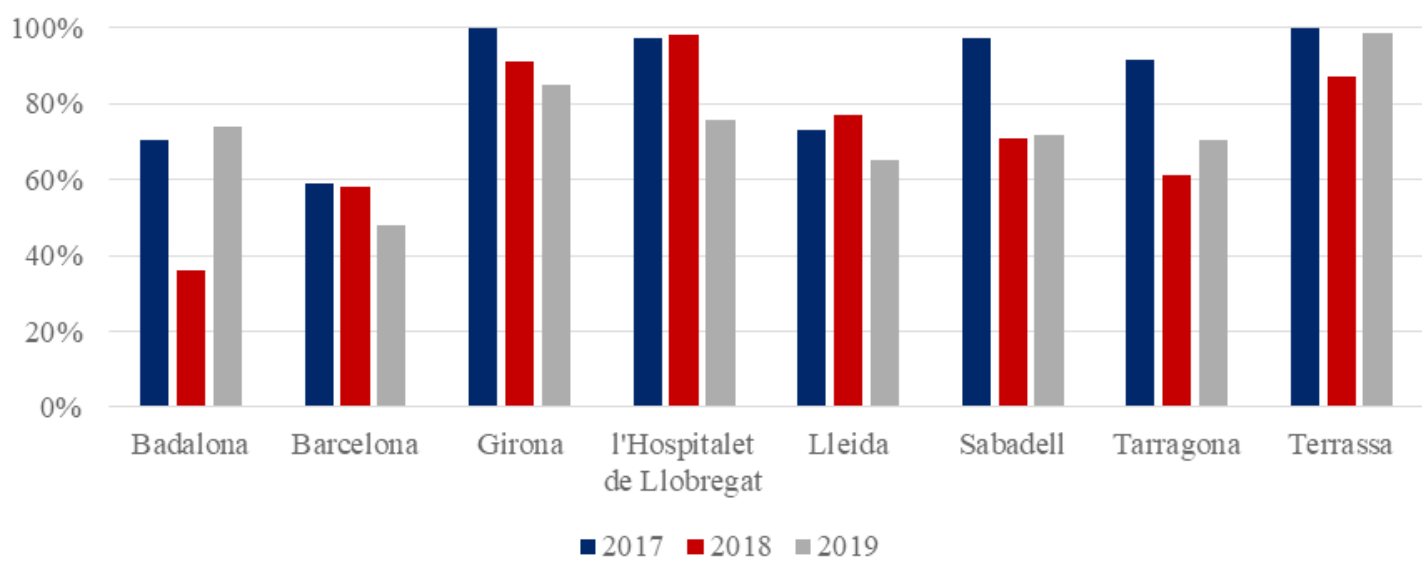

Fuente: Elaboración propia a partir de los datos de la Plataforma de Contratación Pública de la Generalitat.

Por lo tanto, el aumento del peso de los criterios AFA en el proceso de adjudicación no viene dado por un aumento en el peso del precio (que muestra una tendencia decreciente en todos los municipios analizados, excepto Badalona), sino por el peso que han asumido otros criterios. En concreto, en 2019, destacan: incremento del servicio $(20,3 \%)$, otras mejoras $(19,2 \%)$, formación y experiencia de los equipos $(16,2 \%)$ e incremento de las actividades (15,0\%). Es importante señalar también en este punto que, de acuerdo con el punto 5.3 del Código de buenas prácticas de la Generalitat, las mejoras en la contratación no deberían implicar horas de servicio sin coste, ya que éstas son inadmisibles según el Código.

\subsubsection{Peso del precio en el conjunto de la evaluación}

El peso del precio en el conjunto del proceso de evaluación varía en función del territorio. En la ciudad de Barcelona se sitúa ligeramente por debajo del $34 \%$. De hecho, Barcelona incorpora en un $26,8 \%$ de los pliegues contractuales estudiados en 2019 , la medida de contratación pública sostenible relativa a la valoración del precio en, máximo, el $35 \%$ del conjunto de los criterios de evaluación de ofertas. En el resto de las ciudades, se observa un significativo aumento del peso del precio en el proceso de adjudicación, llegando al $62,2 \%$ en el año 2019. Es interesante observar cómo se produce este cambio de tendencia en el 2019, ya que hasta ese momento el peso del precio en el proceso de evaluación se había reducido al 40,6 \% (Figura 7).

Figura 7. Peso del precio en el proceso de eVAluación en función del terRitorio, 2017-2019

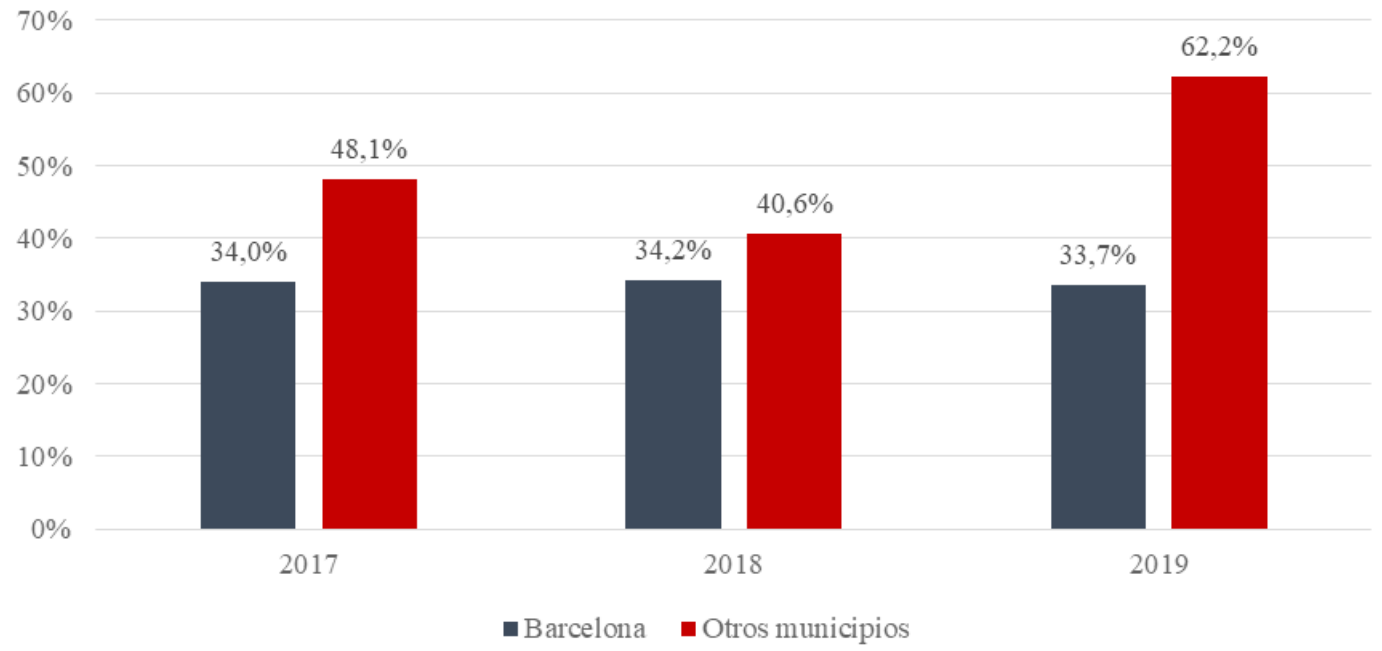

Fuente: Elaboración propia a partir de los datos de la Plataforma de Contratación Pública de la Generalitat. 
REALA. Nueva Época - N. 16, octubre 2021 - ISSN: 1989-8975 - DOI: https://doi.org/10.24965/reala.i16.10960 - [Págs. 150-172]

¿Las cláusulas sociales en los contratos públicos favorecen a las entidades del tercer sector? La evolución de la contratación...

Marc Martí-Costa / Cecilia Isabel Conde López

\subsubsection{Fórmulas en el proceso de evaluación}

El peso del precio puede verse incrementado o reducido en función de la fórmula económica que sea aplicada a la hora de evaluar las ofertas recibidas. La oferta económicamente más baja recibe la máxima puntuación establecida por este criterio y se convierte en referente a la hora de calcular el peso del resto de ofertas. Las puntuaciones obtenidas por el resto de las ofertas están condicionadas en función del tipo de fórmula aplicada, las cuales provocan diferencias significativas en los resultados. Por lo tanto, la cuestión de la fórmula matemática es también un factor determinante.

El "Código de Buenas Prácticas en la contratación pública de los servicios de atención a las personas" (2015), en su apartado 5.4. establece la necesidad de que los licitadores apliquen fórmulas proporcionales que sirvan para favorecer la «concurrencia pero sin permitir que diferencias poco significativas se traduzcan en puntuaciones notoriamente desproporcionadas». Para este artículo, se han sistematizado cinco tipos de fórmulas aplicadas en los casos de estudios (ninguna de ellas es la recomendada por el Código de Buenas Prácticas):

TABLA 3. TIPO de FórmULAS APLICADAS EN LOS CONTRATOS DE ESTUdIO

\begin{tabular}{|c|c|c|}
\hline Fórmula 1 & \multicolumn{2}{|c|}{$[(A-B) /(A-C)]{ }^{*} P$} \\
\hline Fórmula 2 & \multicolumn{2}{|c|}{$\left((A-B){ }^{*} P\right) /(A-C)$} \\
\hline \multirow[t]{2}{*}{ Fórmula 3} & $(\mathrm{Pmb} \geq \mathrm{Br})$ & $B p=(B p / P) * P$ \\
\hline & $(\mathrm{Pmb}<\mathrm{Br})$ & $B p=(B p / B) * P$ \\
\hline Fórmula 4 & \multicolumn{2}{|c|}{$(((A-B) /(A-C))+(C / B)) / 2) * P$} \\
\hline Fórmula 5 & $\mathrm{P} *(\mathrm{C} / \mathrm{B})$ & $(C * P) / B$ \\
\hline
\end{tabular}

Fuente: Elaboración propia a partir de los datos de la Plataforma de Contratación Pública de la Generalitat.

Entre los años 2017 y 2019, la fórmula aplicada por la Generalitat (fórmula 5), representa el 31,3\% de los expedientes, ante un $45,4 \%$ referente a la fórmula 1 . Sin embargo, aquí es clave el peso de la ciudad de Barcelona, donde estas fórmulas representan el $73,2 \%$. El resto de los municipios utilizan de forma mayoritaria $(77,6 \%)$ la fórmula 5 , la aplicada también por la Generalitat de Catalunya. En la ciudad de Barcelona, la fórmula 1 se ha ido consolidando hasta posicionarse como la única fórmula utilizada durante el año 2019.

Figura 8. Evolución fórmulas utilizadas en los CASOS De BARCELONA, 2017-2019

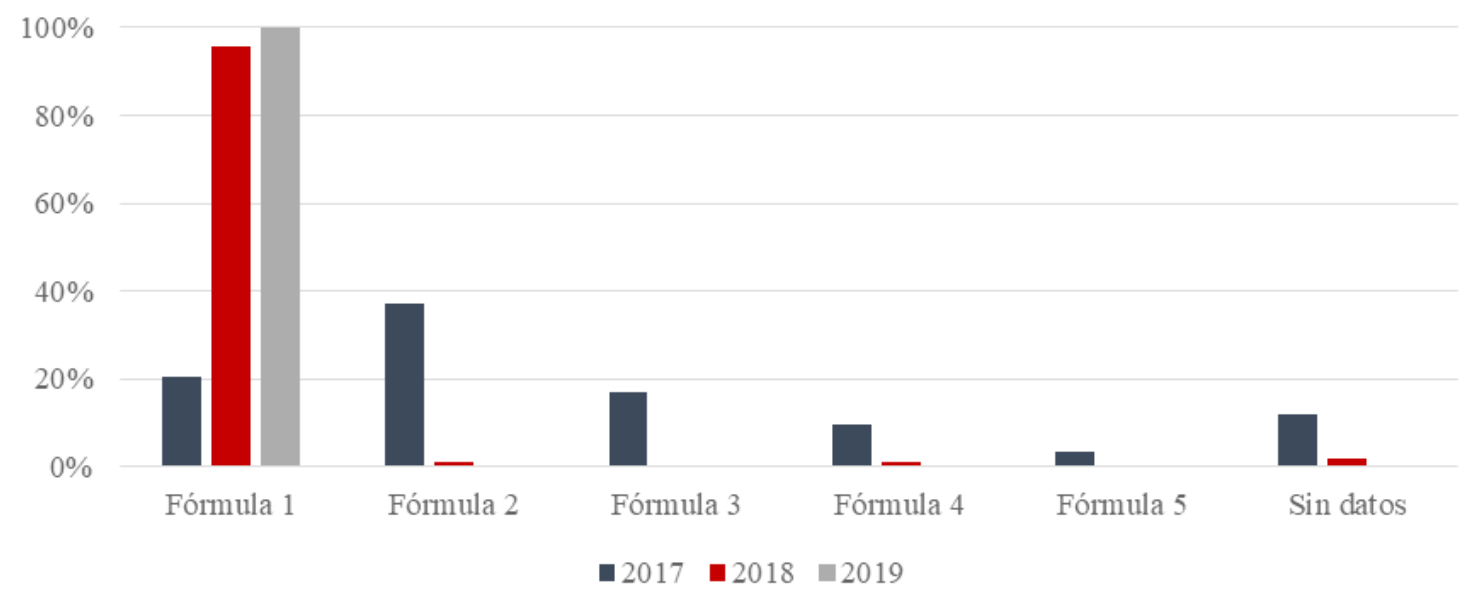

Fuente: Elaboración propia a partir de los datos de la Plataforma de Contratación Pública de la Generalitat. 
REALA. Nueva Época - N. 16, octubre 2021 - ISSN: 1989-8975 - DOI: https://doi.org/10.24965/reala.i16.10960 - [Págs. 150-172]

¿Las cláusulas sociales en los contratos públicos favorecen a las entidades del tercer sector? La evolución de la contratación..

Marc Martí-Costa / Cecilia Isabel Conde López

\subsection{Evolución en la naturaleza jurídica de los licitantes y adjudicatarios}

\subsubsection{Evolución de los licitantes}

Habiendo analizado los cambios introducidos en la contratación pública y las características de la estructura del proceso de evaluación, este capítulo aborda uno de los principales ámbitos de interés de este estudio: la identificación de la naturaleza de los licitadores en los concursos de contratación pública y los casos en los que se produce concurrencia competitiva entre entidades del Tercer Sector Social (en adelante, entidades del TSS) y empresas mercantiles.

\section{Figura 9. Evolución del volumen de contratos SEgún La naturaleza de los concursantes, EN BARCELONA, 2017-2019}

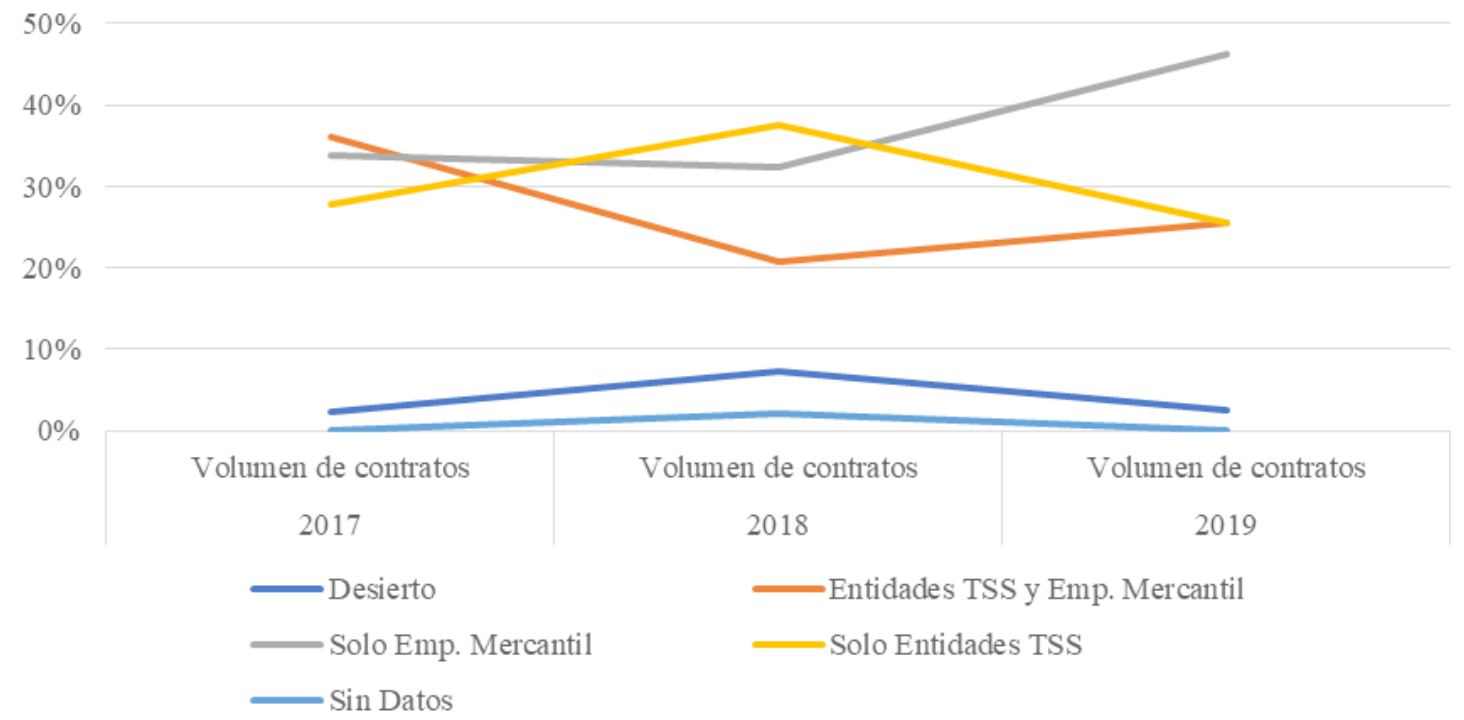

Fuente: Elaboración propia a partir de los datos de la Plataforma de Contratación Pública de la Generalitat.

En el año 2017 en Barcelona, las empresas mercantiles se presentaban en exclusividad con un porcentaje relativamente superior a las entidades del TSS; una tendencia que se invierte en el 2018 , cuando las entidades se presentan en un porcentaje superior a las empresas mercantiles, y que en el año 2019 marca un significativo cambio de tendencia: mientras crece el número de empresas mercantiles que se presentan a los concursos de este tipo de servicios, decae el número de entidades TSS que lo hace (46,3\% para las empresas mercantiles y $25,6 \%$ para las entidades del TSS) (Figura 9). Una tendencia que se extrapola al conjunto de casos.

La concurrencia entre entidades del TSS y empresas mercantiles representa también un 25,6\% de los casos de 2019; una cifra que ha ido variando a lo largo de este periodo analizado.

La diferencia fundamental, sin embargo, radica en base a los presupuestos de licitación de estos expedientes, donde las empresas mercantiles consiguen el 73,6\% del conjunto de casos de 2019 ante el 14,7\% de las entidades del TSS (Figura 10). En términos presupuestarios, pues, el cambio de tendencia el 2019 se hace mucho más evidente.

Es significativo también observar la falta de concurrencia entre empresas mercantiles y entidades del TSS en el total de casos analizados, que se da en 326 de los casos del estudio (el 75,6\%). De estos, en 162 (un 37,6\%) sólo se presentan empresas mercantiles, y en 135 (un 31,6\%) sólo se presentan entidades del TSS. La concurrencia entre entidades del TSS y empresas mercantiles, por el conjunto de casos sólo se produce en 105 casos, significando un $24,4 \%$ del conjunto total de expedientes (Figura 9). En términos presupuestarios, la concurrencia se produce en expedientes por valor de $46.064 .504,9 €$, lo que significa el $24,9 \%$ del total del estudio.

Con respecto al resto de ciudades analizadas, las empresas mercantiles muestran una tendencia positiva, al analizar el volumen de casos, al contrario de lo que sucede con las entidades sociales. Si se analiza el volumen presupuestario, las empresas mercantiles se presentan al $46,2 \%$ del presupuesto, y las entidades al $14,1 \%$. 
REALA. Nueva Época - N. 16, octubre 2021 - ISSN: 1989-8975 - DOI: https://doi.org/10.24965/reala.i16.10960 - [Págs. 150-172] ¿Las cláusulas sociales en los contratos públicos favorecen a las entidades del tercer sector? La evolución de la contratación...

Marc Martí-Costa / Cecilia Isabel Conde López

Figura 10. Evolución de Los PREsupuestos de Licitación SEgún NATURALeza de Los Concursantes, EN BARCELONA, 2017-2019

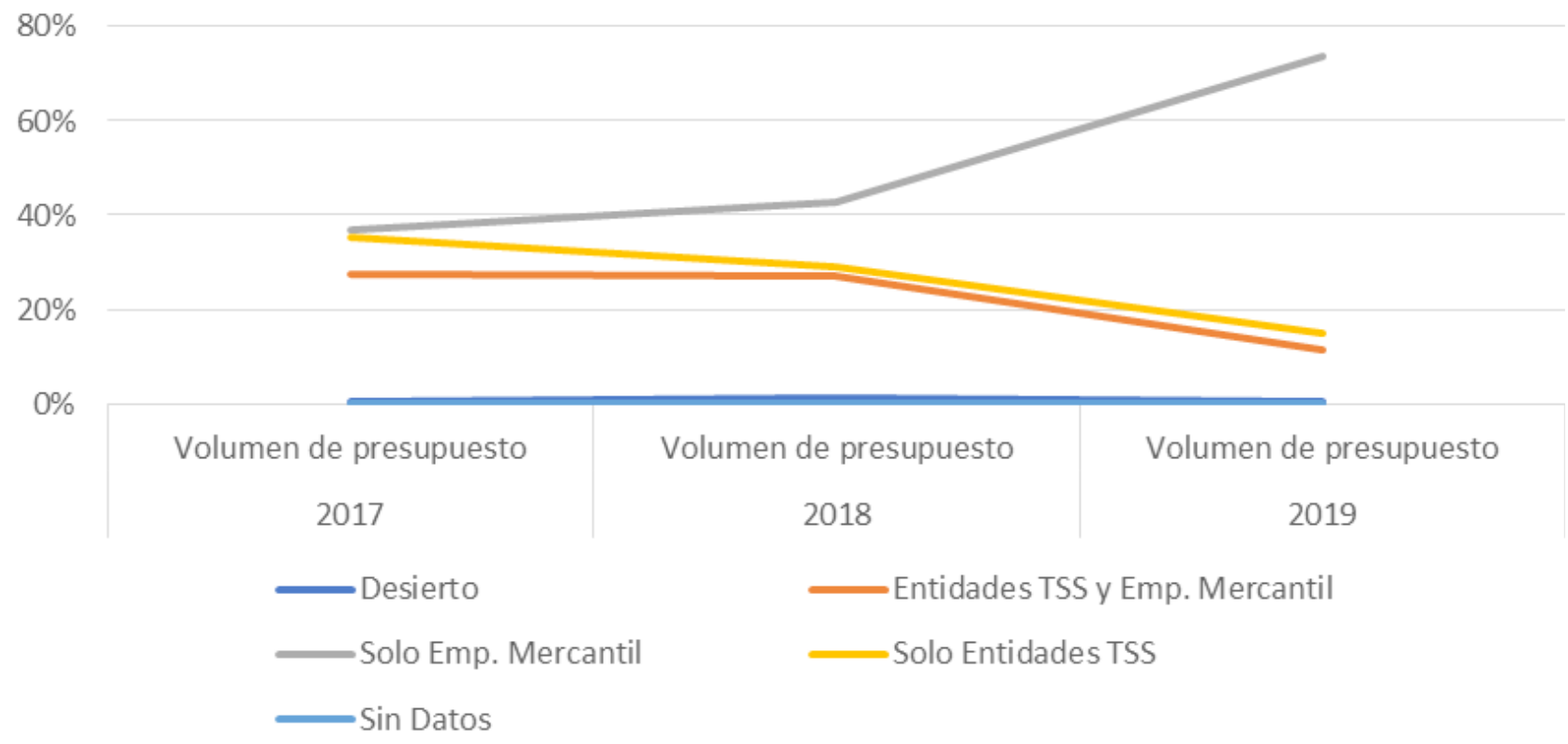

Fuente: Elaboración propia a partir de los datos de la Plataforma de Contratación Pública de la Generalitat.

La mayor parte de los casos de concurrencia entre empresas mercantiles y entidades del TSS se producen en la ciudad de Barcelona con 71 casos (lo que representa el 14,8\% del presupuesto total) (Figura 10). En el resto de los municipios, se identifican 34 casos de concurrencia, cifra que significa el $10,1 \%$ del conjunto. De modo que hay mayor concurrencia en la ciudad de Barcelona que en el resto de los municipios, tanto a nivel de cantidad de contratos, como a nivel de presupuesto.

Figura 11. Peso de los casos sin concurRencia y los de concurRencia entre empresas mercantiles Y ENTIDADES DEL TSS, SEGÚN TERRITORIO, 2017-2019

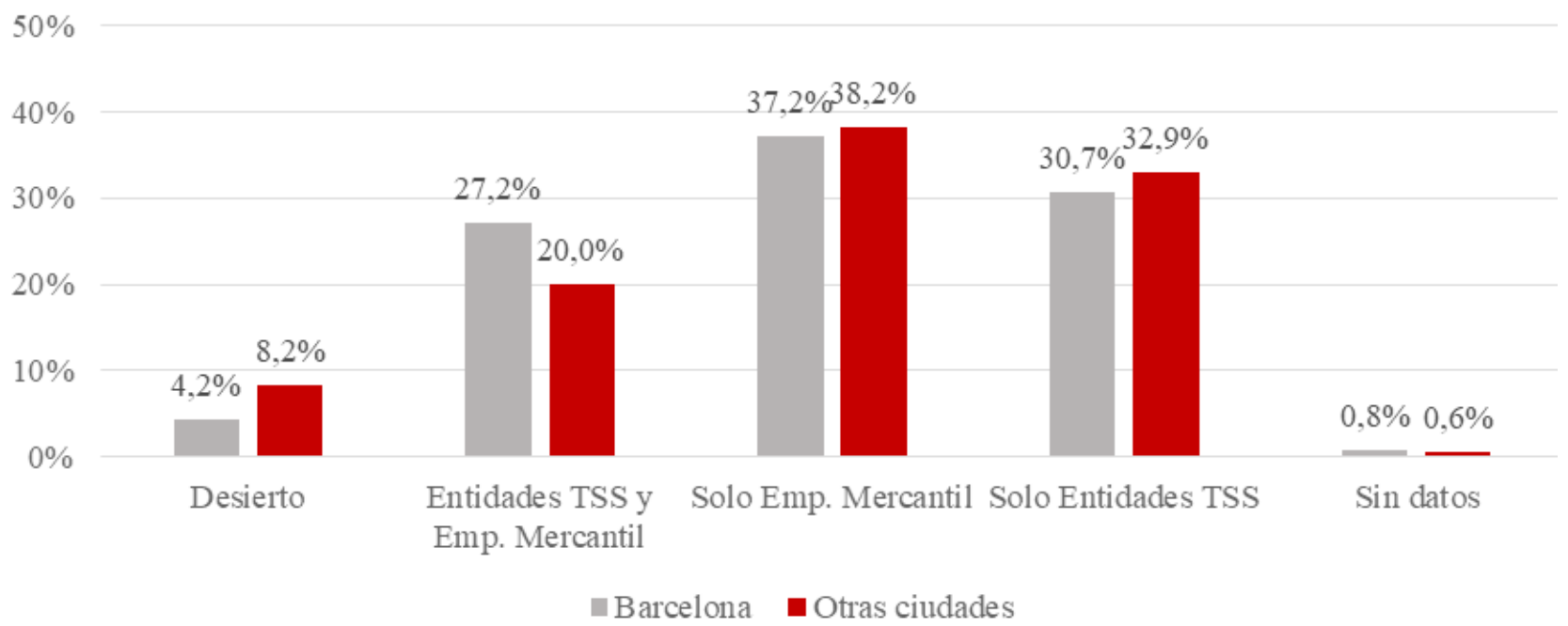

Fuente: Elaboración propia a partir de los datos de la Plataforma de Contratación Pública de la Generalitat.

Así, el porcentaje de EM que se presentan a concursos sin competencia es ligeramente inferior en Barcelona (37,2\%), que en el resto de los municipios (38,2\%). Lo mismo ocurre con los concursos donde 
REALA. Nueva Época - N. 16, octubre 2021 - ISSN: 1989-8975 - DOI: https://doi.org/10.24965/reala.i16.10960 - [Págs. 150-172] ¿Las cláusulas sociales en los contratos públicos favorecen a las entidades del tercer sector? La evolución de la contratación..

sólo se presentan entidades del TSS: en Barcelona se da en 30,7\%, y en el resto de los municipios, en un $32,9 \%$ (Figura 11).

Barcelona presenta un $27,2 \%$ de casos de concurrencia entre empresas mercantiles y entidades del tercer sector, ante un $20 \%$ del resto de municipios del estudio. También es relevante observar el volumen de casos que quedan desiertos en Barcelona $(4,2 \%)$, lo que supone la mitad de lo que representa en el resto del territorio analizado $(8,2 \%)$ (Figura 11$)$.

Si analizamos la intensidad de la concurrencia, se ha observado la mediana de licitadores por contrato (Tabla 4). En el caso de Barcelona, lo que se observa es un aumento de la competencia en aquellos contratos donde se presentan entidades del TSS y las empresas mercantiles mientras que se desciende ligeramente en los contratos donde solo se presentan un mismo tipo de licitantes. Es una tendencia similar al resto de municipios, si bien en el resto de municipios aumenta más la competencia entre empresas mercantiles que en la ciudad de Barcelona.

Tabla 4. Media de licitadores según la naturaleza del licitador de los Casos, 2017-2019

\begin{tabular}{lcccrrr}
\hline & & Barcelona & \multicolumn{3}{c}{ Otros municipios } \\
\hline Naturaleza del licitador & $\mathbf{2 0 1 7}$ & $\mathbf{2 0 1 8}$ & $\mathbf{2 0 1 9}$ & $\mathbf{2 0 1 7}$ & $\mathbf{2 0 1 8}$ & $\mathbf{2 0 1 9}$ \\
\hline Solo Empresa Mercantil & 1,57 & 1,26 & 1,24 & 1,8 & 3,2 & 2,3 \\
\hline Solo Entidad TSS & 1,18 & 1,78 & 1,14 & 1,2 & 1,2 & 1,1 \\
\hline Entidad TSS y empresas mercantiles & 2,90 & 2,65 & 3,48 & 3,1 & 2,9 & 3,9 \\
\hline Total general & $\mathbf{1 , 9 6}$ & $\mathbf{1 , 7 9}$ & $\mathbf{1 , 8 0}$ & $\mathbf{1 , 8}$ & $\mathbf{2 , 2}$ & $\mathbf{2 , 3}$ \\
\hline
\end{tabular}

Fuente: Elaboración propia a partir de los datos de la Plataforma de Contratación Pública de la Generalitat.

Finalmente, se ha explorado en qué rangos presupuestarios se dan los casos de concurrencia entre las entidades del TSS y las empresas mercantiles. Los contratos con un importe hasta $100.000 €$ son los más frecuentes, representando el $46,7 \%$ del conjunto de la muestra de concursos donde hay concurrencia. Sin embargo, a nivel territorial hay diferencias significativas en este tipo de contratos, ya que en la ciudad de Barcelona representan el 38,0 \% frente el 64,7\% del resto de municipios, en el período analizado 2017-2019 (Tabla 5).

En el rango presupuestario $500.001 €$ y 1 millón de euros, es en el que nos encontramos mayores diferencias entre Barcelona y el resto de los municipios: Barcelona representa un $23,9 \%$ de la muestra, mientras que en el resto de las ciudades se reduce a sólo un $8,8 \%$.

TABLA 5. VOLUMEN Y PORCENTAJE DE LOS CASOS EN CONCURRENCIA ENTRE ENTIDADES DEL TERCER SECTOR Y EMPRESAS MERCANTILES EN FUNCIÓN DEL RANGO DE PRESUPUESTO, SEGÚN TERRITORIO, 2017-2019

\begin{tabular}{|c|c|c|c|c|c|c|c|c|c|c|}
\hline \multirow[b]{2}{*}{ Territorio } & \multicolumn{2}{|c|}{ Hasta $100.000 €$} & \multicolumn{2}{|c|}{$\begin{array}{c}\text { Entre } 100.001 € \\
\text { y } 500.000 €\end{array}$} & \multicolumn{2}{|c|}{$\begin{array}{c}\text { Entre } 500.001 € \\
\text { y } 1 \mathrm{M} €\end{array}$} & \multicolumn{2}{|c|}{ Más de $1 \mathrm{M} €$} & \multicolumn{2}{|c|}{ Total general } \\
\hline & $\begin{array}{c}\text { Volumen } \\
\text { de } \\
\text { casos }\end{array}$ & $\%$ & $\begin{array}{c}\text { Volumen } \\
\text { de } \\
\text { casos }\end{array}$ & $\%$ & $\begin{array}{c}\text { Volumen } \\
\text { de } \\
\text { casos }\end{array}$ & $\%$ & $\begin{array}{c}\text { Volumen } \\
\text { de } \\
\text { casos }\end{array}$ & $\%$ & $\begin{array}{c}\text { Volumen } \\
\text { de } \\
\text { casos }\end{array}$ & $\%$ \\
\hline Barcelona & 27 & $38,0 \%$ & 21 & $29,6 \%$ & 17 & $23,9 \%$ & 6 & $8,5 \%$ & 71 & $100 \%$ \\
\hline $\begin{array}{l}\text { Otros } \\
\text { municipios }\end{array}$ & 22 & $64,7 \%$ & 7 & $20,6 \%$ & 3 & $8,8 \%$ & 2 & $5,9 \%$ & 34 & $100 \%$ \\
\hline $\begin{array}{l}\text { Total } \\
\text { general }\end{array}$ & 49 & $46,7 \%$ & 28 & $26,7 \%$ & 20 & $19,0 \%$ & 8 & $7,6 \%$ & 105 & $100 \%$ \\
\hline
\end{tabular}

Fuente: Elaboración propia a partir de los datos de la Plataforma de Contratación Pública de la Generalitat. 
REALA. Nueva Época - N. 16, octubre 2021 - ISSN: 1989-8975 - DOI: https://doi.org/10.24965/reala.i16.10960 - [Págs. 150-172] ¿Las cláusulas sociales en los contratos públicos favorecen a las entidades del tercer sector? La evolución de la contratación...

Marc Martí-Costa / Cecilia Isabel Conde López

\subsubsection{Evolución de los adjudicatarios}

A continuación, analizamos de forma evolutiva los ganadores de los contratos según el número de casos ganados y según el volumen presupuestario ganado.

Aunque el volumen de contratos ganados por las empresas mercantiles se había reducido en el 2018 (41\%), aumenta considerablemente en 2019 (54\%). Y de forma inversa, el aumento del volumen de contratos que las entidades del TSS habían alcanzado en el 2018 (49,5\%), cae en 2019 (38,8\%) (Figura 12).

Figura 12. Evolución del volumen de CASOS GANAdOS, SEgún LA NATURALeza del Adjudicatario,
EN BARCELONA, 2017-2019

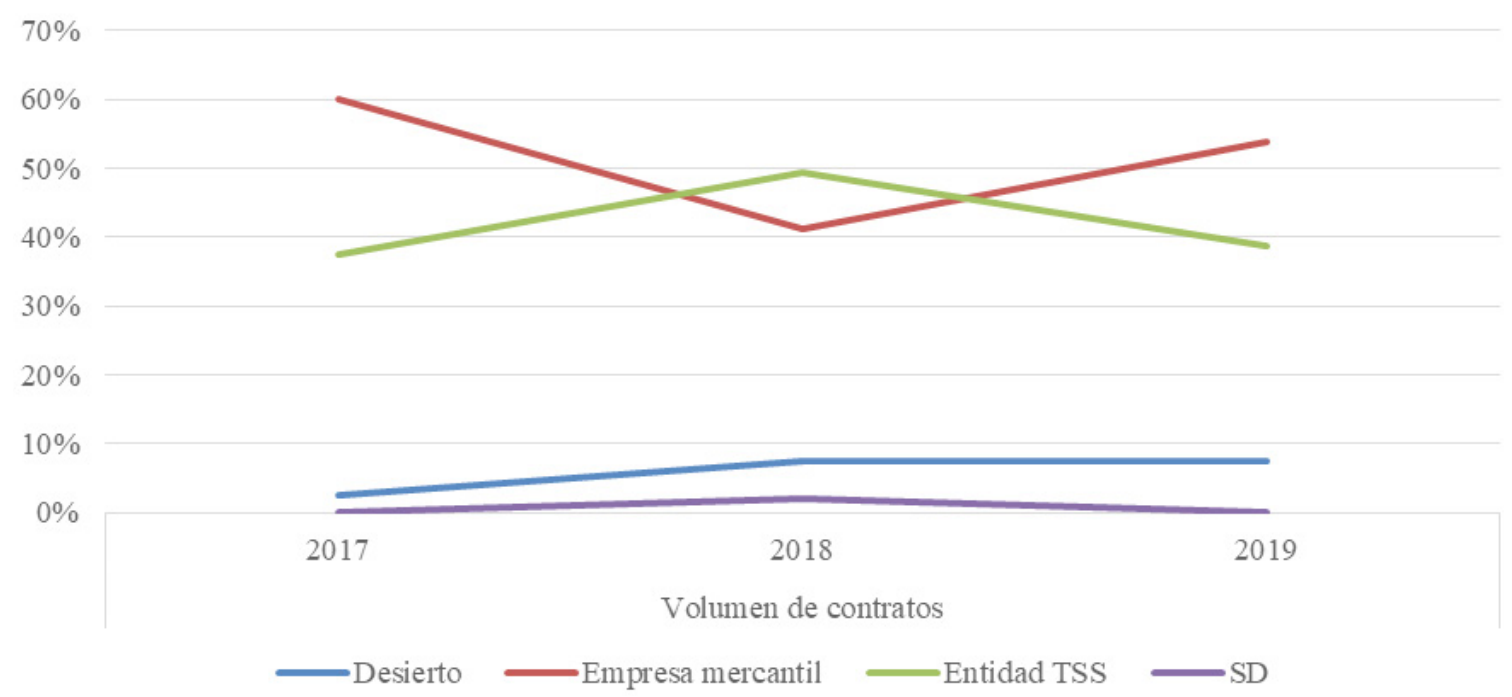

Fuente: Elaboración propia a partir de los datos de la Plataforma de Contratación Pública de la Generalitat.

A nivel presupuestario, se evidencia una tendencia creciente en el volumen presupuestario que ganan las empresas mercantiles $(74,1 \%)$ desde el año 2017 . Y, por el contrario, una tendencia decreciente en el presupuesto ganado por las entidades del TSS, en el año $2019(24,5 \%)$.

Figura 13. EVOLUCIÓN DEL VOLUMEN PRESUPUESTARIO GANADO, SEGÚN LA NATURALEZA DEL ADJUdicATARIO, EN BARCELONA, 2017-2019

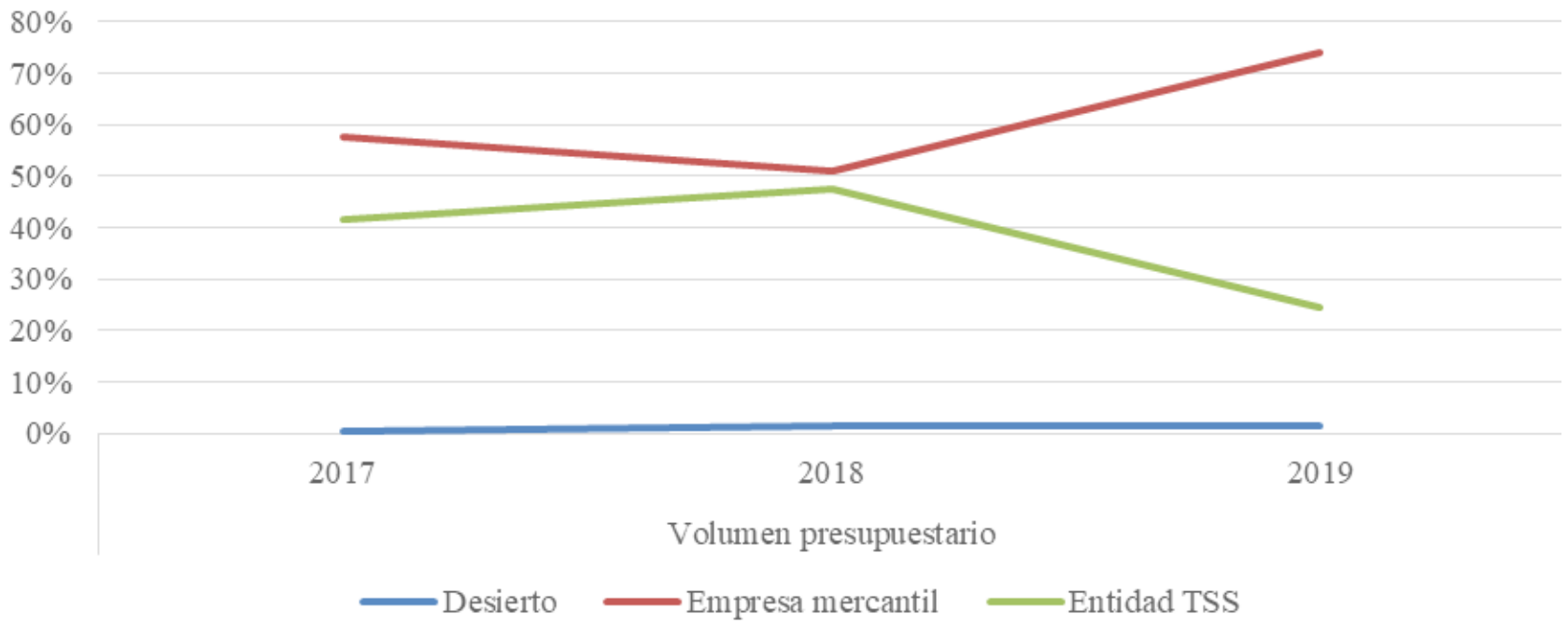

Fuente: Elaboración propia a partir de los datos de la Plataforma de Contratación Pública de la Generalitat. 
REALA. Nueva Época - N. 16, octubre 2021 - ISSN: 1989-8975 - DOI: https://doi.org/10.24965/reala.i16.10960 - [Págs. 150-172]

¿Las cláusulas sociales en los contratos públicos favorecen a las entidades del tercer sector? La evolución de la contratación..

Marc Martí-Costa / Cecilia Isabel Conde López

Cuando se analiza la evolución de los adjudicatarios en las otras ciudades, excluyendo Barcelona, se observa que en volumen de contratos las empresas mercantiles ganan más que las entidades del TSS. En volumen presupuestario, destaca el porcentaje de casos que quedan desiertos, que llega casi al $50 \%$. Si se excluyen estos contratos que quedan desiertos, las empresas mercantiles siguen ganando más que las entidades del tercer sector en el resto de municipios, tanto en volumen presupuestario, como en número de casos.

\section{FIgURA 14. VOLUMEN PRESUPUESTARIO DE LOS GANADORES EN LOS PROCEDIMIENTOS DE CONTRATACIÓN CUANDO HAY COMPETENCIA ENTRE EMPRESAS MERCANTILES Y ENTIDADES DEL TSS, SEGÚN NATURALEZA DEL ADJUDICATARIO Y TERRITORIO, 2017-2019}

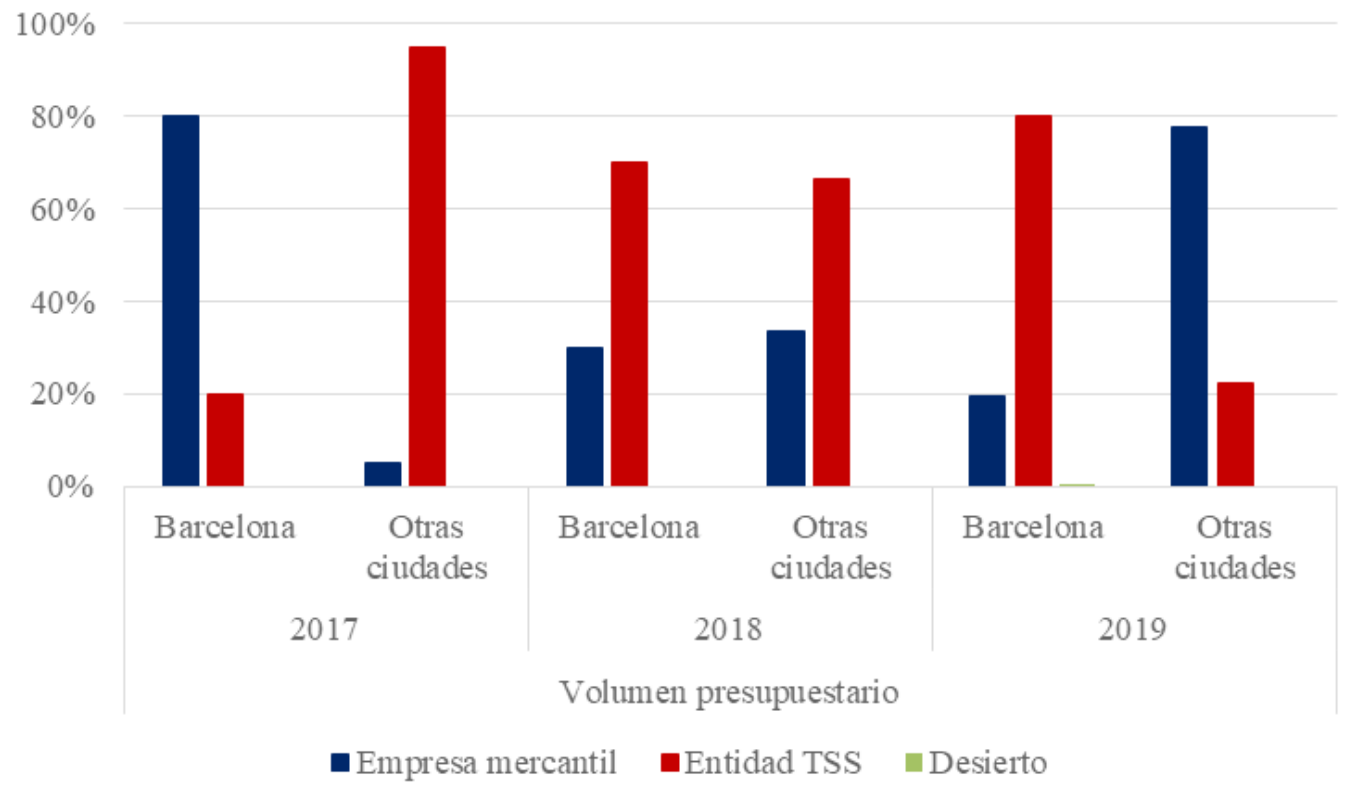

Fuente: Elaboración propia a partir de los datos de la Plataforma de Contratación Pública de la Generalitat.

En la Figura 14 observamos la evolución diferencial entre las empresas mercantiles y las entidades del TSS según municipios cuando hay competencia entre ellas. En el caso de Barcelona, a lo largo de estos tres años, las entidades del TSS se han vuelto más competitivas frente a las empresas mercantiles. Mientras que en 2017 conseguían el $20 \%$ del presupuesto total, en 2019 llegan hasta el $80 \%$. En cambio, en el resto de municipios, mientras que en 2017 conseguían el 95\% del presupuesto, en 2019 solo consiguen el 22,2\%.

En conclusión, Barcelona es la ciudad donde se produce más concurrencia entre estos dos tipos de licitadores, y no solo en volumen de casos, sino, especialmente, en el volumen presupuestario. Las entidades del TSS, además, muestran en los contratos de Barcelona una capacidad creciente de ganar los concursos de contratación pública cuando compiten con empresas mercantiles.

\subsection{Explorando la relación entre las condiciones de los contratos y los resultados de las adjudicaciones}

A partir del análisis realizado, se observa que los cambios introducidos en la contratación pública de este tipo de servicios por el ayuntamiento de Barcelona (aumento MCPS, inclusión estructura de costes, inclusión criterio puntuación mínimo, aumento del número de contratos con presupuesto de licitación igual o inferior a $100.00 €$, división entre los criterios AFA y los JdV) hayan tenido un efecto en el aumento de las entidades del tercer sector que se presentan y ganan este tipo de concursos. En otras palabras, a pesar de la introducción de este tipo de medidas que pretenden una acción positiva a favor de los licitadores que demuestren conciencia social y unas buenas prácticas (como podrían ser las entidades del TSS), los datos muestran que, en realidad, crece el volumen presupuestario de este tipo de contratos que ganan las empresas mercantiles mientras decae el volumen que ganan las entidades del TSS. En Barcelona, crece el volumen presupuestario al que se presentan las empresas mercantiles $(73,8 \%)$ y se reduce al que lo hacen las entidades del 
REALA. Nueva Época - N. 16, octubre 2021 - ISSN: 1989-8975 - DOI: https://doi.org/10.24965/reala.i16.10960 - [Págs. 150-172]

¿Las cláusulas sociales en los contratos públicos favorecen a las entidades del tercer sector? La evolución de la contratación..

Marc Martí-Costa / Cecilia Isabel Conde López

TSS (14,8\%). Se evidencia también el ascenso considerable del porcentaje de casos ganados, en el 2019, por las empresas mercantiles en Barcelona (46,3\%, frente a un 32,3\% en el 2018 ) y de forma inversa, el descenso que han sufrido las entidades del tercer sector, cuyo porcentaje de casos ganados se reduce al $25,6 \%$ (frente al $37,5 \%$ del 2018).

Figura 15. CRITERIOS DETERMinANTES A LA HORA DE RESOlVER LAS ADJUDICACIONES EN LOS CASOS DE BARCELONA, 2017-2019

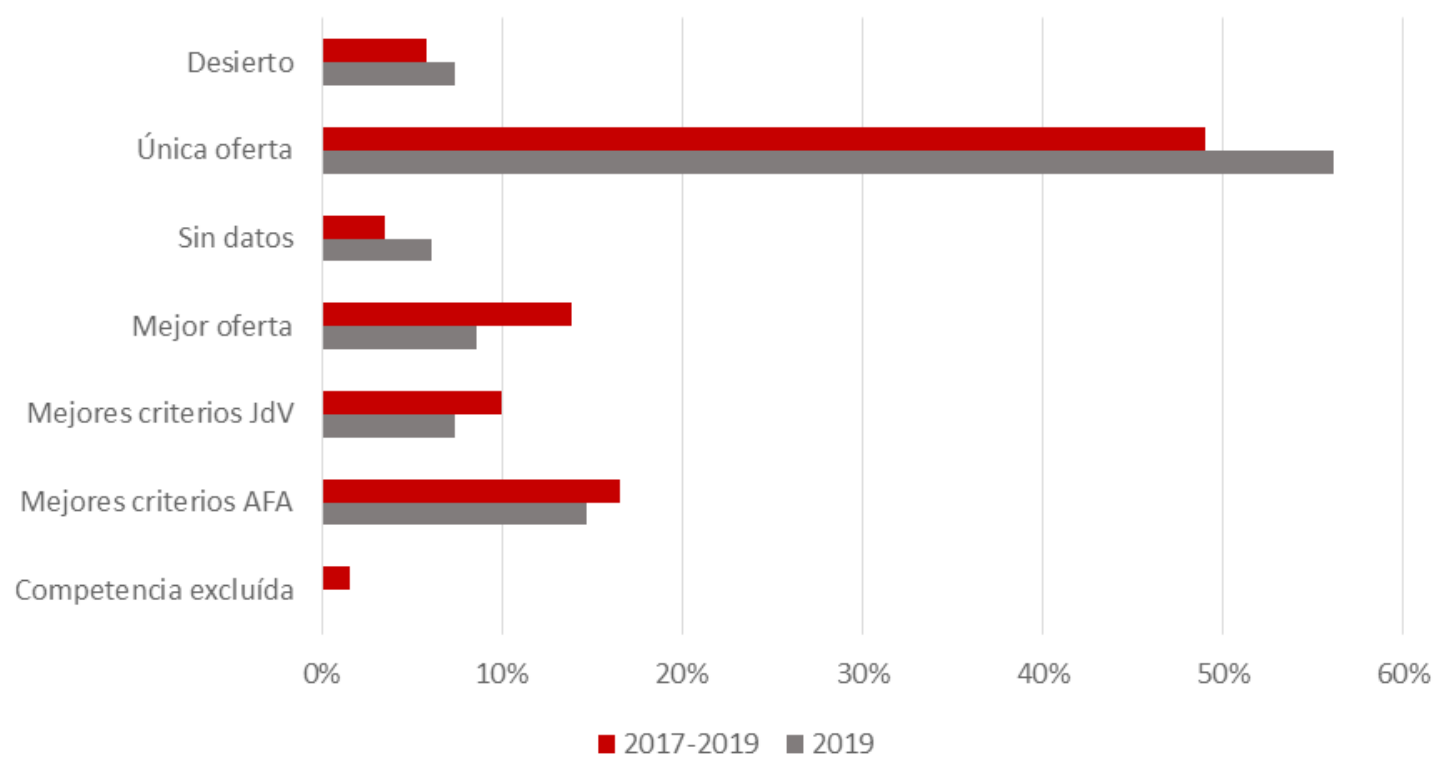

Fuente: Elaboración propia a partir de los datos de la Plataforma de Contratación Pública de la Generalitat.

Sin embargo, también observamos en el caso de Barcelona, a diferencia de otros municipios que no han introducido con tanta intensidad cláusulas sociales, que las entidades del TSS muestran una creciente capacidad de ganar los concursos de contratación pública en concurrencia con empresas mercantiles durante los últimos años. Se debe recordar, a pesar de ello, que la situación más repetida y determinante a la hora de adjudicar los concursos en Barcelona es el hecho de que sólo haya una única oferta, ya sea por parte de empresas mercantiles o de entidades del TSS (Figura 15).

En conjunto, las empresas mercantiles están ganando terreno frente a las entidades del TSS en la obtención de contratos de servicios de atención a las personas en Barcelona aunque hayan aumentado las cálusulas sociales. Específicamente en los casos de concurrencia entre empresas mercantiles y entidades del tercer sector, por contra, las entidades del TSS han mostrado una evolución mucho más positiva, tanto en número de casos como, sobre todo, en volumen presupuestario. Esto se podría explicar seguramente por la moderación del criterio precio en Barcelona a pesar del aumento del peso de los criterios AFA. Los resultados demuestran que las empresas mercantiles se muestran especialmente competitivas ante los criterios económicos, y las entidades del TSS continúan mostrando un mayor grado de competitividad en función de la oferta técnica.

Así las cosas, ¿en qué casos los cambios introducidos y el diseño de la estructura del proceso de evaluación de la oferta suponen, verdaderamente, una acción positiva hacia las entidades del TSS? En el siguiente apartado se identifican factores y/o dinámicas que han demostrado una acción positiva efectiva a favor de los licitadores sin ánimo de lucro. A continuación analizamos de forma conjunta los contratos de todos los municipios y todos los años para aumentar el número de casos donde el adjudicatario es una entidad del TSS y facilitar el análisis de los factores de éxito. Los resultados que se presentan son por lo tanto aplicables al conjunto de los municipios estudiados.

\subsection{Factores que suponen una efectiva acción positiva hacia las entidades del tercer sector}

En el estudio realizado se han detectado una serie de situaciones o factores en las que se produce una acción positiva hacia las entidades del tercer sector social. En concreto son: 1) cuando los JdV son los 
REALA. Nueva Época - N. 16, octubre 2021 - ISSN: 1989-8975 - DOI: https://doi.org/10.24965/reala.i16.10960 - [Págs. 150-172]

¿Las cláusulas sociales en los contratos públicos favorecen a las entidades del tercer sector? La evolución de la contratación...

Marc Martí-Costa / Cecilia Isabel Conde López

factores determinantes de los concursos en concurrencia entre entidades del TSS y empresas mecantiles; 2) cuando el peso de los criterios AFA es inferior a $51 \%$; 3) cuando el peso del precio es inferior al $50 \%$; 4) cuando se aplica la fórmula cinco; 5) cuando el presupuesto de licitación del contrato (+ IVA) no supera los $100.000 €$.

\section{JdV como factor determinante de los concursos en concurrencia entre empresas mercantiles y entidades del TSS}

En los casos de concurrencia, en concreto, las entidades del TSS ganan cuando presentan una mejor oferta general ${ }^{7}$ ( $24 \%$ de los casos). Sin embargo, la diferencia realmente significativa la encontramos cuando el factor determinante son los criterios AFA o los relativos a JdV. En el primer caso, las empresas mercantiles se muestran más competitivas, ganando en el $44,9 \%$ de los casos frente al $26 \%$ de las entidades del TSS. Por el contrario, en los concursos donde los criterios evaluables mediante JdV han sido determinantes, las entidades del TSS ganan en un $40 \%$ de los casos ante un $28,6 \%$ cuando lo hacen las empresas mercantiles, en el conjunto de los casos.

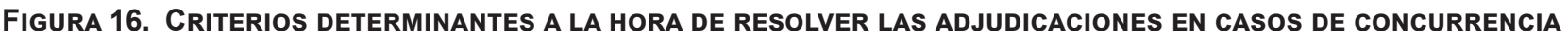
ENTRE ENTIDADES DEL TSS Y EMPRESAS MERCANTILES EN FUNCIÓN DE LA NATURALEZA DEL ADJUDICATARIO EN EL CONJUNTO DE LOS CASOS, 2017-2019

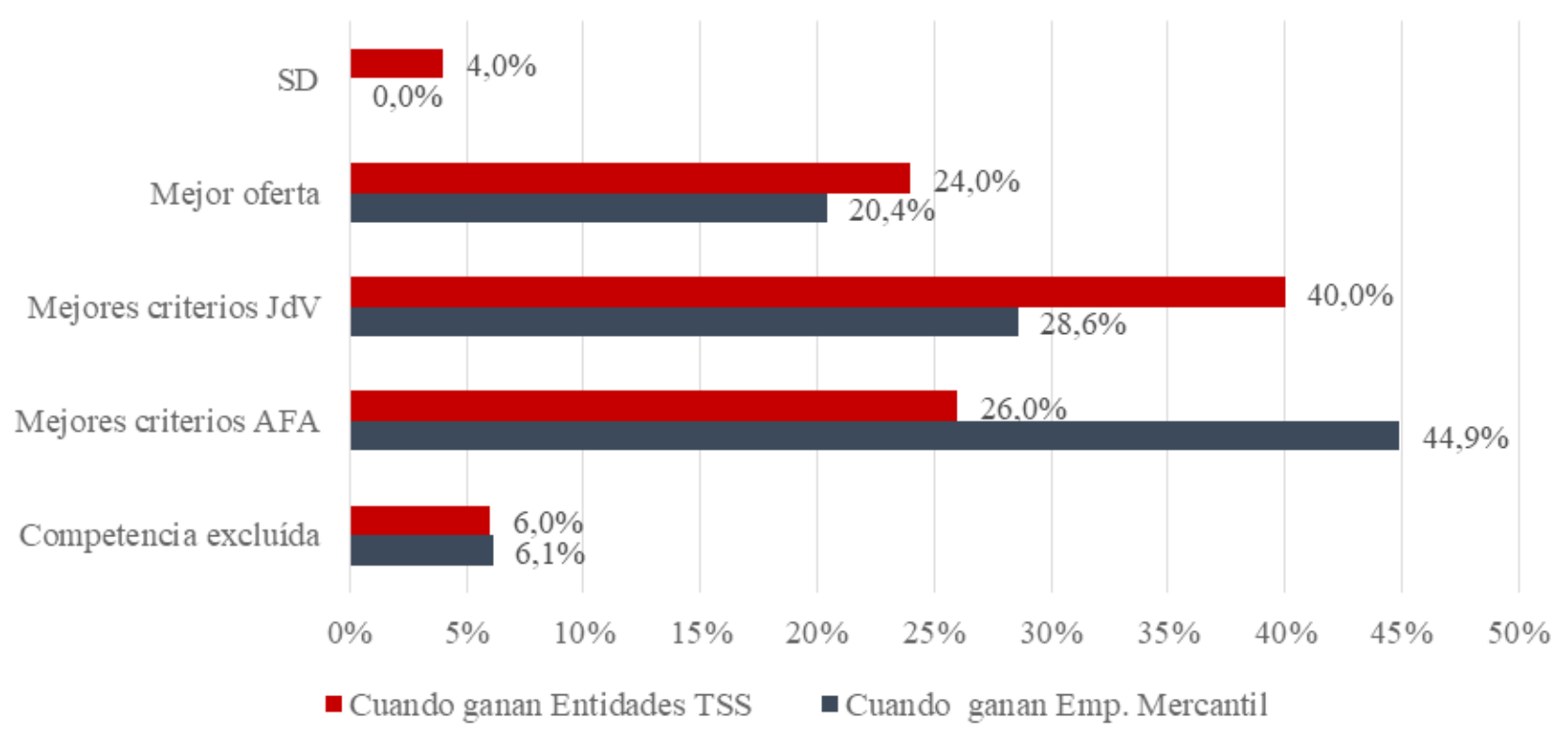

Fuente: Elaboración propia a partir de los datos de la Plataforma de Contratación Pública de la Generalitat.

\section{Cuando AFA inferior a $51 \%$}

Cuando el peso del AFA es igual o inferior al $51 \%$ las entidades del TSS ganan un mayor volumen número de contratos, especialmente significativo en cuanto al número de contratos, con un $54 \%$ frente a un $38 \%$ de las empresas mercantiles. Pero en cambio, en términos presupuestarios, el porcentaje que se lleva la empresa mercantil es superior al que acaban consiguiendo las entidades TSS. Esta tendencia cambia cuando los criterios AFA se sitúan por encima del $51 \%$ : las empresas mercantiles ganan en un $56,8 \%$ de los casos ante un $33,1 \%$ con respecto a las entidades del TSS. Esta diferencia es aún mayor si atendemos al volumen presupuestario, donde las EM ganan el $63,4 \%$ frente al $24,6 \%$.

7 Esto es, que sea la mejor oferta no significa necesariamente que sea la mejor en todos los aspectos, sino que gana porque es lo bastante competitiva como para imponerse al resto. 
REALA. Nueva Época - N. 16, octubre 2021 - ISSN: 1989-8975 - DOI: https://doi.org/10.24965/reala.i16.10960 - [Págs. 150-172] ¿Las cláusulas sociales en los contratos públicos favorecen a las entidades del tercer sector? La evolución de la contratación... Marc Martí-Costa / Cecilia Isabel Conde López

TABLA 6. QUIÉn GANA LOS PROCEdIMIENTOS DE CONTRATACIÓN CUANDO LOS CRITERIOS AFA SE SITÚAN POR DEBAJO O POR ENCIMA DEL $51 \%$, SEgÚN LA NATURALEZA DEL ADJUDICATARIO. SEGÚN NÚMERO DE CONTRATOS Y VOLUMEN PRESUPUESTARIO, EN EL CONJUNTO TOTAL DE CASOS, 2017-2019

\begin{tabular}{|c|c|c|c|c|c|c|c|c|}
\hline & \multicolumn{4}{|c|}{ AFA igual o inferior al $51 \%$} & \multicolumn{4}{|c|}{ AFA superior al $51 \%$} \\
\hline & \multicolumn{2}{|c|}{$\begin{array}{c}\text { Número } \\
\text { de contratos }\end{array}$} & \multicolumn{2}{|c|}{$\begin{array}{c}\text { Volumen } \\
\text { presupuestario }\end{array}$} & \multicolumn{2}{|c|}{$\begin{array}{c}\text { Número } \\
\text { de contratos }\end{array}$} & \multicolumn{2}{|c|}{$\begin{array}{c}\text { Volumen } \\
\text { presupuestario }\end{array}$} \\
\hline & $\begin{array}{c}\text { Valor } \\
\text { absoluto }\end{array}$ & $\%$ & $\begin{array}{c}\text { Valor } \\
\text { absoluto }\end{array}$ & $\%$ & $\begin{array}{c}\text { Valor } \\
\text { absoluto }\end{array}$ & $\%$ & $\begin{array}{c}\text { Valor } \\
\text { absoluto }\end{array}$ & $\%$ \\
\hline $\begin{array}{l}\text { Empresa } \\
\text { Mercantil }\end{array}$ & 57 & $38 \%$ & $44.912 .839,8$ & $54,8 \%$ & 150 & $56,4 \%$ & $59.172 .796,8$ & $62,7 \%$ \\
\hline Entidad TSS & 81 & $54 \%$ & $33.810 .666,3$ & $41,2 \%$ & 89 & $33,5 \%$ & $23.904 .320,2$ & $25,3 \%$ \\
\hline $\begin{array}{l}\text { UTE Entidad } \\
\text { TSS y empresa } \\
\text { mercantil }\end{array}$ & 3 & $2 \%$ & $2.544 .055,6$ & $3,1 \%$ & 4 & $1,5 \%$ & $2.897 .273,4$ & $3,1 \%$ \\
\hline Desierto/SD & 9 & $6 \%$ & $729.336,3$ & $0,9 \%$ & 23 & $8,6 \%$ & $8.434 .977,2$ & $8,9 \%$ \\
\hline Total general & 150 & $100 \%$ & $81.996 .898,1$ & $100 \%$ & 266 & $100 \%$ & $94.409 .367,7 €$ & $100 \%$ \\
\hline
\end{tabular}

Fuente: Elaboración propia a partir de los datos de la Plataforma de Contratación Pública de la Generalitat.

\section{Cuando peso del precio inferior a $35 \%$}

En las ciudades que no son Barcelona, cuando el peso del precio no supera el $35 \%$ del total del conjunto de la oferta, los ganadores de estos concursos son las entidades del TSS. En cambio, cuando el peso del precio supera el $35 \%$ ganan las empresas mercantiles. En Barcelona, sin embargo, este factor no supone una acción positiva para las entidades del TSS: tanto si el peso del precio es inferior como superior al $35 \%$, las empresas mercantiles son las ganadoras de los concursos, posiblemente por la incidencia simultánea de otros factores.

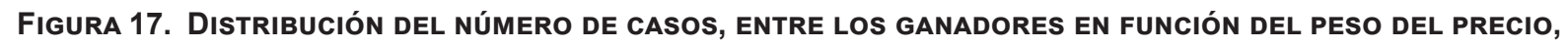
SEGÚN TERRITORIO, CONJUNTO DE CASOS 2017-2019

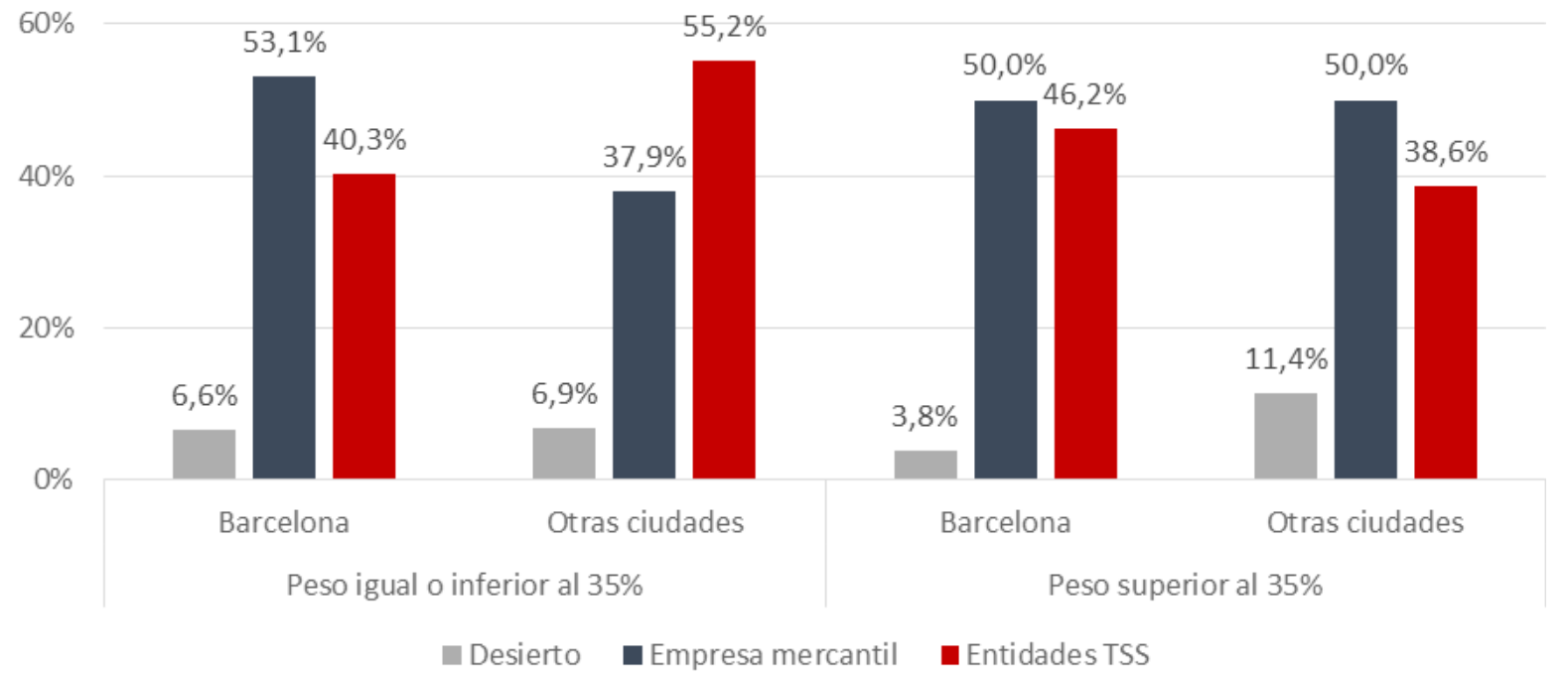

Fuente: Elaboración propia a partir de los datos de la Plataforma de Contratación Pública de la Generalitat.

Es relevante mencionar también que cuando el peso del precio es inferior al $35 \%$, las entidades del TSS en las ciudades que no son Barcelona, se llevan el mayor porcentaje presupuestario. 
REALA. Nueva Época - N. 16, octubre 2021 - ISSN: 1989-8975 - DOI: https://doi.org/10.24965/reala.i16.10960 - [Págs. 150-172] ¿Las cláusulas sociales en los contratos públicos favorecen a las entidades del tercer sector? La evolución de la contratación..

Marc Martí-Costa / Cecilia Isabel Conde López

\section{Cuando se aplica la Fórmula 5}

FiguRA 18. EFECTOS DE LAS DIFERENTES FÓRMULAS PARA VALORAR LAS OFERTAS ECONÓMICAS

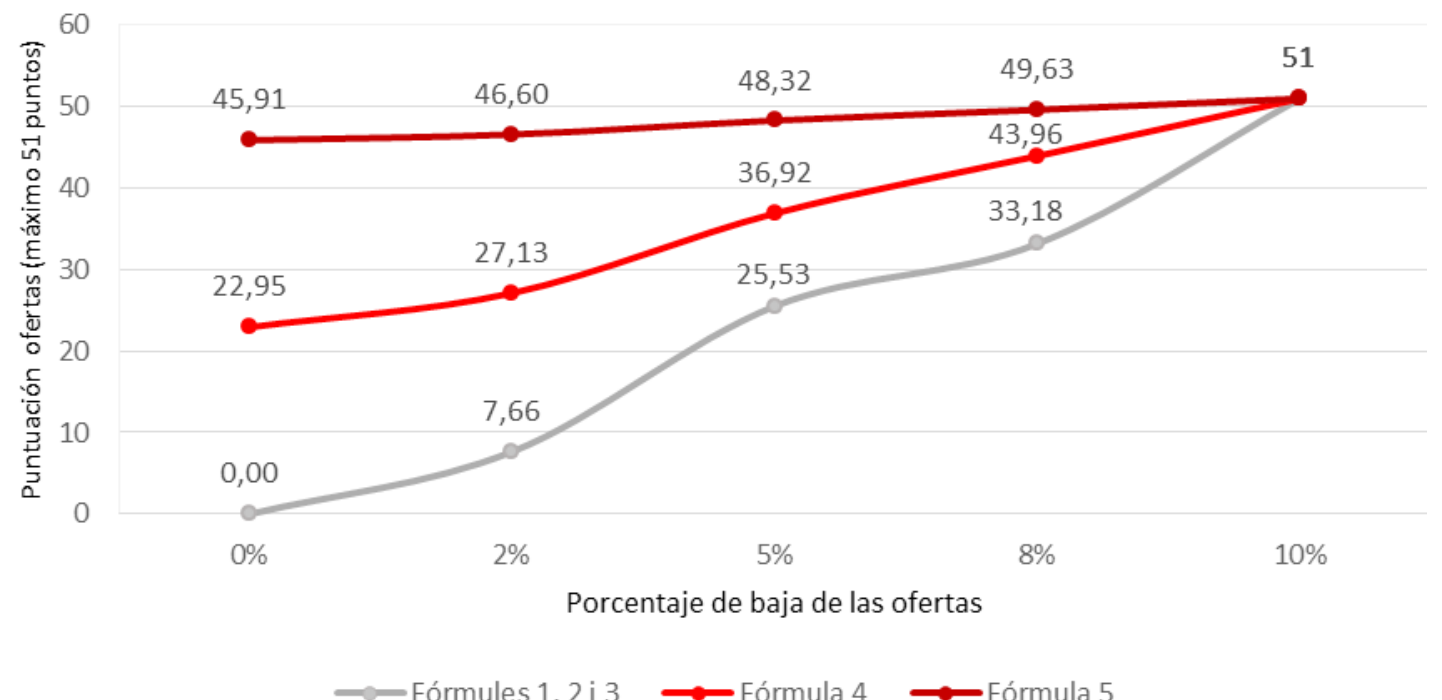

Fuente: Elaboración propia a partir de los datos de la Plataforma de Contractació Pública de la Generalitat.

En cuanto a la fórmula utilizada, las diferencias generadas por la aplicación de la fórmula matemática pueden resultar un factor determinante en la mayor parte de los casos. Las fórmulas 1, 2 y 3 establecen diferencias significativas entre la oferta más económica y el resto de las ofertas. Por otra parte, las otras dos (la 4 y la 5) no penalizan tanto al resto de ofertas. En concreto, Barcelona utiliza fórmulas matemáticas (fundamentalmente la fórmula 1) que favorece la oferta económicamente más ventajosa y penaliza significativamente al resto.

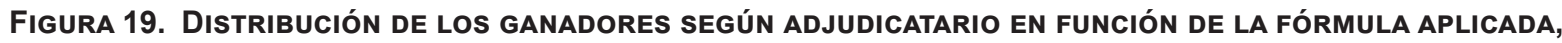
EN LAS CIUDADES QUE NO SON BARCELONA, 2017-2019

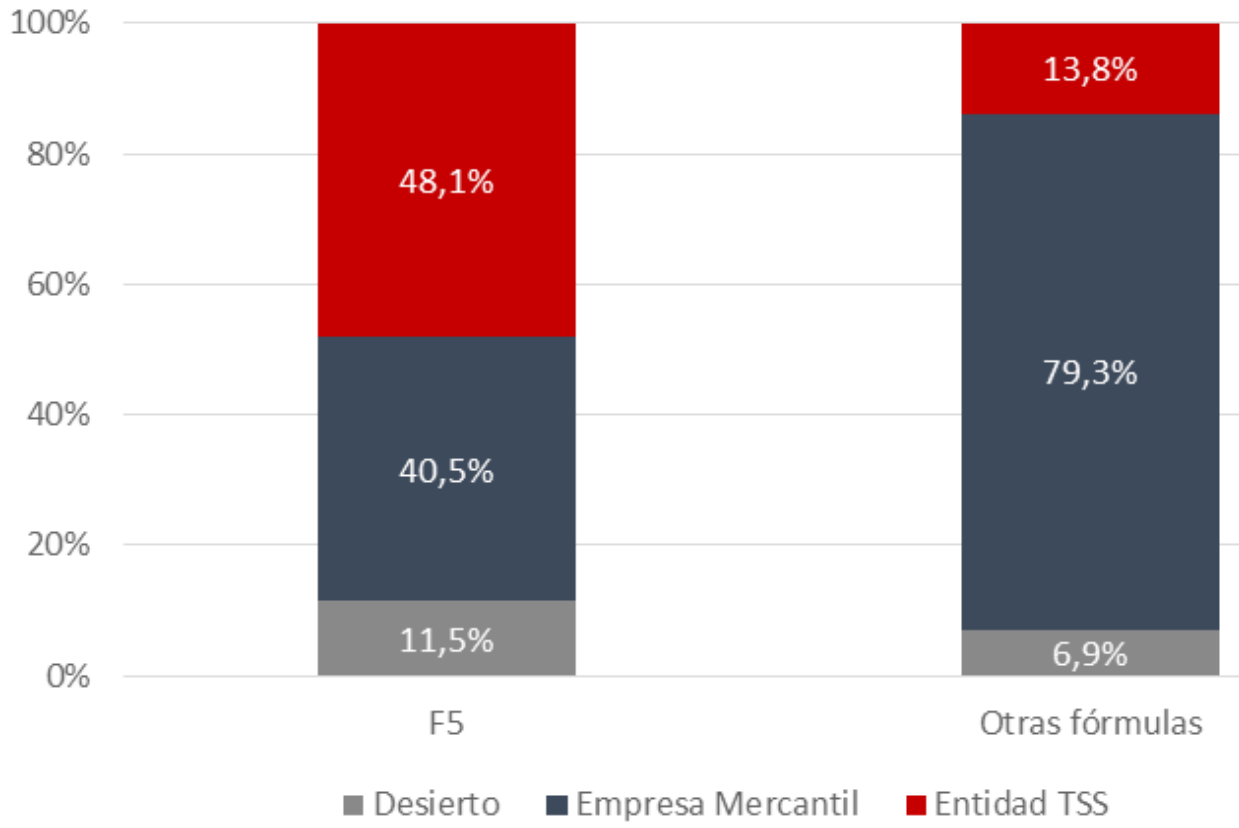

Fuente: Elaboración propia a partir de los datos de la Plataforma de Contractació Pública de la Generalitat. 
REALA. Nueva Época - N. 16, octubre 2021 - ISSN: 1989-8975 - DOI: https://doi.org/10.24965/reala.i16.10960 - [Págs. 150-172]

¿Las cláusulas sociales en los contratos públicos favorecen a las entidades del tercer sector? La evolución de la contratación...

Marc Martí-Costa / Cecilia Isabel Conde López

El Código de Buenas prácticas recomienda utilizar la Fórmula $\mathrm{Pi}=\mathrm{Cr}$ * $(100-100$ * $(\mathrm{Bp}-\mathrm{PMB}))$. Sin embargo, esta fórmula no se ha aplicado en ninguno de los casos utilizados. De entre las fórmulas sistematizadas, la menos penalizadora, la F5, la utilizada por la Generalitat de Catalunya, es con la que las entidades del TSS salen más beneficiadas. En concreto, ganan casi la mitad de los contratos $(48,1 \%)$, frente al $13,8 \%$ de victoria que obtienen cuando se aplican otras fórmulas. Al utilizar otras fórmulas diferentes a la F5, las principales beneficiadas (con un $79,3 \%$ de casos ganados) son las empresas mercantiles.

\section{Cuando presupuesto de licitación de los contratos no supera los $100.000 €$}

En ciertos rangos presupuestarios, las entidades del TSS también se muestran más competitivas. Por ejemplo, en los contratos hasta $100.000 €$. Por el contrario, las empresas mercantiles muestran una superioridad evidente en los contratos de valores superiores, especialmente en los del rango entre $500.001 €$ y un millón de euros. Aun así, en Barcelona, el $44 \%$ de los casos de más de un millón de presupuesto lo ganan las entidades del TSS. En cambio, las entidades TSS ganan, en todos los municipios, la contratación inferior a $100.000 €$ (Figura 20).

Si se analiza según los rangos presupuestarios de los casos en concurrencia entre las empresas mercantil y las entidades del TSS, se observa que las entidades del TSS ganan mayoritariamente los contratos de menos de $100.000 €$ y también los de entre medio millón y un millón de euros. Los contratos en concurrencia que superan el millón de euros, las empresas mercantiles y las entidades del TSS llevan el mismo número de contratos. En cambio, los casos en concurrencia con valor entre $100.001 €$ y $500.000 €$ ganan fundamentalmente las empresas mercantiles.

Figura 20. RANGo presupuestario de los contratos, en El CONJUNTO de CASOS, SEGÚN ADJUDICATARIO, 2017-2019

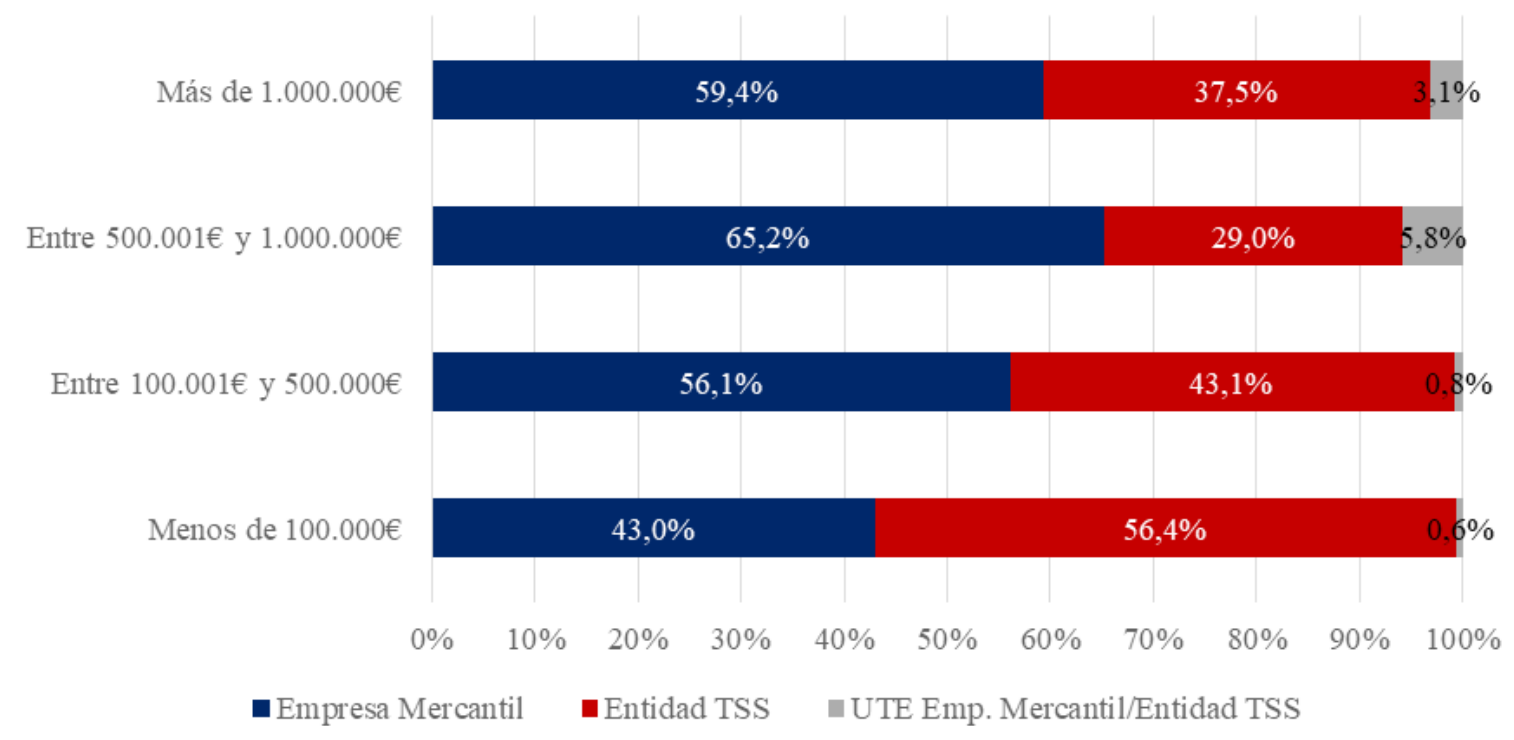

Fuente: Elaboración propia a partir de los datos de la Plataforma de Contratación Pública de la Generalitat.

\section{CONCLUSIONES}

Los cambios introducidos en la contratación pública se han producido en un breve periodo de tiempo en el que los licitadores, ya sean empresas mercantiles o entidades del tercer sector, se han tenido que adaptar a los nuevos marcos normativos de contratación.

El análisis realizado sobre los cambios introducidos en la contratación pública y en el diseño de los pliegos contractuales de los servicios de atención a las personas muestra dinámicas particulares en los procesos de evaluación y adjudicación de los contratos de este ámbito, atendiendo a la naturaleza jurídica de los licitadores y los adjudicatarios. 
REALA. Nueva Época - N. 16, octubre 2021 - ISSN: 1989-8975 - DOI: https://doi.org/10.24965/reala.i16.10960 - [Págs. 150-172]

¿Las cláusulas sociales en los contratos públicos favorecen a las entidades del tercer sector? La evolución de la contratación...

Marc Martí-Costa / Cecilia Isabel Conde López

Si bien los cambios introducidos en la contratación pública no pretenden generar una desigualdad de trato de las empresas licitadoras según su naturaleza jurídica, sí pretenden generar una acción positiva a favor de las empresas que demuestren conciencia social y unas buenas prácticas, tal y como lo recoge la Guía de contratación pública social Barcelona $(2018)^{8}$. Sin embargo, los resultados muestran que solo en situaciones muy concretas y minoritarias las entidades del TSS, en las que la conciencia social forma parte de su naturaleza, se ven favorecidas por los cambios introducidos.

Por ejemplo, la introducción de innovaciones en los pliegues contractuales como la presencia de la estructura de costes o la inclusión del criterio de puntuación mínima en los procesos de adjudicación son criterios que presentan una tendencia creciente, y que, a su vez, pueden suponer un aspecto positivo para las entidades del tercer sector, al permitir corroborar si los salarios del personal han sido calculados en función de un convenio colectivo específico y su adecuación al servicio, y al exigir un mínimo de calidad en las ofertas presentadas. Sin embargo, son medidas aun minoritarias, particularmente fuera del ayuntamiento de Barcelona.

En cuanto a la inclusión de las cláusulas sociales en los contratos, éstas sólo se aplican de forma mayoritaria por parte del ayuntamiento de Barcelona. Una de estas medidas es la valoración máxima del precio en un $35 \%$ en el conjunto de la oferta. Barcelona es la única ciudad de las analizadas que, gracias a la inclusión de esta cláusula, mantiene a raja tabla el peso del precio por debajo del $35 \%$. En el resto de las ciudades, la media es de un $50,8 \%$ del total de la oferta, a pesar de que el "Código de Buenas prácticas en la contratación pública de los servicios de atención a las personas" recomienda, en su apartado 5.1, que el precio ofrecido por los licitadores no tenga un peso específico superior al $40 \%$ para la determinación de la oferta económicamente más ventajosa, y que una parte de los criterios objetivos no sea exclusivamente el criterio precio, dentro de los criterios AFA.

El precio, por tanto, sigue siendo un factor muy importante dentro del proceso de evaluación de ofertas y de adjudicación de los contratos. De hecho, en el periodo de tiempo analizado, el peso de los criterios AFA ha crecido con respecto a los Juicios de Valor, lo que favorece que las empresas mercantiles ganen las licitaciones, ante las entidades del TSS. Especialmente, cuando la ponderación que reciben los criterios AFA en el conjunto del proceso de evaluación supera el $51 \%$ del total, así como cuando el peso del precio es superior al $50 \%$ del total. La única excepción a este resultado se da cuando el peso de los criterios AFA es inferior al $51 \%$. En este caso, las entidades del TSS ganan en volumen de contratos, pero en volumen presupuestario sigue dominando la empresa mercantil.

De acuerdo con la Ley 9/2017, cuando hay más de un criterio de adjudicación, si el órgano de contratación no quiere establecer un comité de expertos, el peso de los criterios sometidos a la fórmula automática debe ser superior al criterio de juicio de valor. Es decir, los criterios AFA siempre prevalecerán ante los juicios de valor, ya sea mediante el peso del precio u otras mejoras. Por lo tanto, según el análisis realizado, mientras en el proceso de evaluación de las ofertas se otorgue más peso a los criterios evaluables automáticamente, que los criterios evaluables por criterios de juicios de valor, las empresas mercantiles seguirán obteniendo más contratos y más presupuesto que las entidades del tercer sector social.

También merece la pena destacar la importancia de los criterios AFA como factores determinantes de la resolución de los contratos; lo cual se da en un $16,8 \%$ de la muestra estudiada, el segundo porcentaje más elevado después de la oferta única. Este porcentaje refuerza, por tanto, una situación de partida desequilibrada, teniendo en cuenta que la capacidad económica de las empresas mercantiles es superior a la de las entidades del TSS, tal y como muestra la capacidad de reducción de los presupuestos de licitación de las empresas mercantiles. En cambio, cuando los criterios relativos a los Juicios de Valor han sido los determinantes de la resolución de los procesos de adjudicación, en cambio, las entidades del tercer sector han salido favorecidas. Sin embargo, estos solo se han dado en un 7,4\% de los casos de 2019.

Por otro lado, la cuestión de la fórmula matemática utilizada a la hora de evaluar las ofertas recibidas es también un factor determinante. El análisis realizado muestra que, en el caso de la ciudad de Barcelona, donde el peso del precio es menor, las fórmulas matemáticas aplicadas favorecen la oferta económicamente más ventajosa y penalizan significativamente al resto. Estos tipos de fórmulas parece que se consolidan en la capital catalana. Mientras que, en el resto de los municipios, predomina una fórmula menos penalizadora, la fórmula 5 (la utilizada por la Generalitat de Catalunya). Ninguna de estas, sin embargo, es la recomenda-

8 Este artículo no entra a valorar los cambios que las características del procedimiento de adjudicación hayan podido suponer en las empresas mercantiles para poder ganar estos concursos. 
REALA. Nueva Época - N. 16, octubre 2021 - ISSN: 1989-8975 - DOI: https://doi.org/10.24965/reala.i16.10960 - [Págs. 150-172] ¿Las cláusulas sociales en los contratos públicos favorecen a las entidades del tercer sector? La evolución de la contratación..

Marc Martí-Costa / Cecilia Isabel Conde López

da por el Código de buenas prácticas en la contratación pública de los servicios de atención a las personas que tiene como objetivo favorecer la concurrencia, pero sin permitir que diferencias poco significativas se traduzcan en puntuaciones notoriamente desproporcionadas entre las ofertas.

En conclusión, los datos muestran que la tendencia general es que las empresas mercantiles se presenten cada vez más y ganen más contratos tanto en Barcelona como en el resto de municipios. Sin embargo, en el caso de Barcelona encontramos una particularidad: cuando hay competencia entre entidades del TSS y empresas mercantiles observamos que las primeras obtienen cada vez más contratos y más volumen presupuestario. Probablemente esta particularidad en Barcelona es debida a la introducción de cláusulas sociales y especialmente a la moderación del factor precio en los contratos. A pesar de este relavante cambio detectado en los últimos años, los contratos donde hay competencia entre entidades del TSS y empresas mercantiles son minoritarios (un $21 \%$ del total en 2019) y además muestran una tendencia descendente. A partir de estos resultados, emergen nuevas preguntas como la de por qué las entidades del tercer sector no se presentan a determinados contratos en Barcelona cuando sus posibilidades de éxito aumentaron. En el resto de municipios, las empresas mercantiles cada vez se presentan y ganan más contratos. A su vez, las empresas del TSS se presentan menos y son cada vez menos exitosas cuando compiten con empresas mercantiles en un contexto de falta de desarrollo de cláusulas sociales.

\section{REFERENCIAS BIBLIOGRÁFICAS}

Ajuntament de Barcelona (2018). Guia de contractació pública social. Consultado el 4 de mayo de 2021. https:// ajuntament.barcelona.cat/contractaciopublica/sites/default/files/guia_contractacio_publica_social_cat_0.pdf

Burzaco Samper, M. (2016). Contrataciones públicas socialmente responsables: la necesidad de reconsiderar el potencial de la contratación pública en la consecución de objetivos sociales. CIRIEC-España. Revista de Economía Pública, Social y Cooperativa. 86, 281-310. http://ciriec-revistaeconomia.es/wp-content/uploads/ CIRIEC_8603_Alarcon.pdf

Calvo Vérgez, J. (2019). La proyección de la nueva Ley 9/2017, de 8 de noviembre, de Contratos del sector público, sobre el ámbito de la Economía social: un nuevo marco regulatorio para las entidades del tercer sector. Revista Aranzadi Doctrinal, 4.

Corretja i Torrens, M. (2018). Principals novetats en la contractació pública dels ens locals. Revista catalana de dret públic, 57, 17-31 http://dx.doi.org/10.2436/rcdp.i57.2018.3163

Dopazo Fraguío, M. (2020). La contratación pública como herramienta para promover la responsabilidad ambiental. Revista catalana de dret ambiental. 11(2), 1-35. https://doi.org/10.17345/rcda2914

Fuentes Gasó, J. R. (2020). El regim jurídic de la provisió de serveis d'atenció a les persones a Catalunya: El concert social després de les directives europees contractació pública. En M. V. Forns Fernández (ed.), C. M. Anleu Hernández y M. Rodríguez Beas (coords.), La protección jurídica de la atención a las personas en materia de servicios sociales. Una perspectiva interdisciplinar (pp. 201-229). Atelier.

Garrido Juncal, A. (2017). Las nuevas formas de gestión de los servicios sociales: elementos para un debate. Revista Catalana de Dret Públic, 55, 84-100. http://dx.doi.org/10.2436/rcdp.i55.2017.3007

La Confederació (30 de diciembre de 2020). Propostes del Tercer Sector Social de Catalunya davant les eleccions al Parlament de Catalunya 14-F 2021. Consultado el 4 de mayo de 2021. https://laconfederacio.org/propostes-deltercer-sector-social-davant-les-eleccions-al-parlament-de-catalunya-del-proper-14-de-febrer-de-2021/

Martí-Costa, M. y Conde López, C. (2021). La contractació pública de serveis d'atenció a les persones, 2019. Institut d'Estudis Regionals i Metropolitans de Barcelona.

Martí-Costa, M. y Ordàs, C. (2019). La contractació pública de serveis a les persones a la província de Barcelona, 2017-2018. Institut d'Estudis Regionals i Metropolitans de Barcelona.

Ordàs, C. (2018). La Contractació Pública a Catalunya en l'àmbit dels Serveis d'Atenció a les Persones, 2017. Institut d'Estudis Regionals i Metropolitans de Barcelona. https://iermb.uab.cat/wp-content/uploads/2019/08/2018_11_12_ Def_La_Contractaci\%C3\%B3_Publica_-a_Catalunya_-en_1\%C3\%A0mbit_dels_SAP_2017_sense_punt_3.pdf

Ordàs, C. (2017). La qualitat de la contractació pública local en l'àmbit dels serveis a les persones. Una anàlisi dels 8 principals ajuntaments de Catalunya. Institut d'Estudis Regionals i Metropolitans de Barcelona.

Solorzano García, M., Navío Marco, J. y Contreras Comeche, R. (2015). Incorporación de valor social a la contratación pública en España: Situación y perspectivas. Revista de Estudios de la Administración Local y Autonómica, 4, 4150. https://doi.org/10.24965/reala.v0i4.10306 